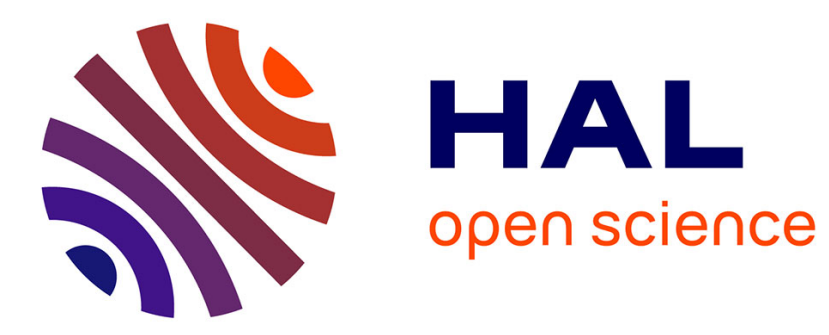

\title{
National Politics and International Agreements
}

Hubert Kempf, Stéphane Rossignol

\section{To cite this version:}

Hubert Kempf, Stéphane Rossignol. National Politics and International Agreements. 2010. halshs00497463

\section{HAL Id: halshs-00497463 \\ https://shs.hal.science/halshs-00497463}

Submitted on 5 Jul 2010

HAL is a multi-disciplinary open access archive for the deposit and dissemination of scientific research documents, whether they are published or not. The documents may come from teaching and research institutions in France or abroad, or from public or private research centers.
L'archive ouverte pluridisciplinaire HAL, est destinée au dépôt et à la diffusion de documents scientifiques de niveau recherche, publiés ou non, émanant des établissements d'enseignement et de recherche français ou étrangers, des laboratoires publics ou privés. 


\section{Documents de Travail du Centre d'Economie de la Sorbonne}
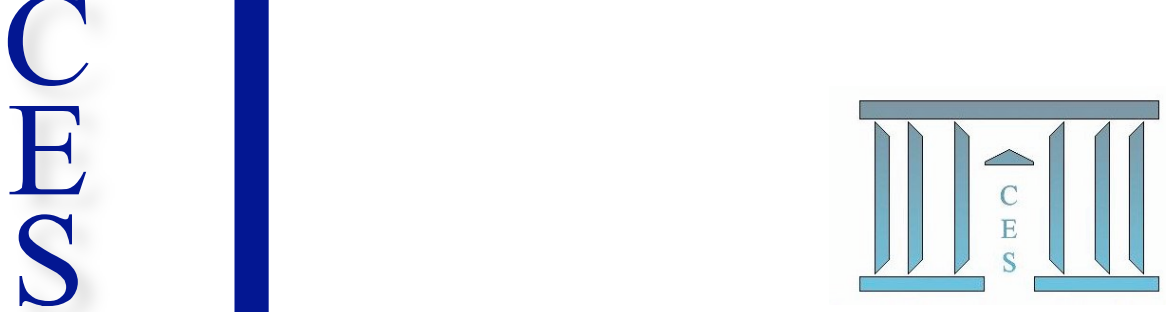

National Politics and International Agreements

Hubert KEMPF, Stéphane ROssIGNOL

2010.52

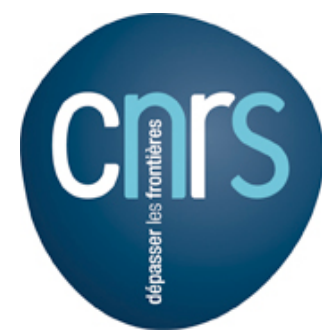




\title{
National Politics and International Agreements.*
}

\author{
Hubert Kempf ${ }^{\dagger} \quad$ Stéphane Rossignol ${ }^{\ddagger}$
}

June 15, 2010

\footnotetext{
${ }^{*}$ We are very grateful to participants to seminars in Université Paris-1 Panthéon-Sorbonne, Vanderbilt University, Stanford University, Banque de France and Washington University, as well as the ASSET 2008 Meeting, and especially to Costas Azariadis, Rick Bond, Matthew Jackson and Grégoire Rota-Graziosi for comments and remarks on an earlier draft of this paper.

${ }^{\dagger}$ Banque de France and Paris School of Economics, kempf@univ-paris1.fr

${ }^{\ddagger}$ LIRAES, Université Paris-Descartes, and Centre d’Economie de la Sorbonne, Université Paris1 Panthéon-Sorbonne, France
} 


\begin{abstract}
International agreements about transnational issues are difficult to reach, as the examples of the Copenhagen summit or the never-ending discussions of the future of the European Union make clear. In this paper we relate this difficulty to the political process and the conflicts of interest attached to an agreement, both within and between national electorates, related to national income distributions. We set up a political economy model of a two-country world economy, where an international agreement on the financing of an international public good has to be negotiated by two elected national delegates. We prove that any international agreement involves higher taxes in both countries than in the case of no-agreement. If reachable, an IA may generate losers in either country. If the political process involves a constraint on tax rates, an agreement may or may not be reached. Finally, when an agreement is reached, it may exhibit strategic delegation when the median voters are the Condorcet winners in both countries: this delegation is the outcome of the struggle by electorates to transfer the tax burden to the other country's taxpayers. In brief, the fate of an international agreements depends on national politics and distributive issues in the involved countries.
\end{abstract}

Keywords: international agreements, bargaining, delegation, voting.

JEL classification: D72, H77.

Résumé : Les accords internationaux sont difficiles à atteindre. Dans cet article, nous expliquons cette difficulté par les processus politiques nationaux et les conflits d'intérêt au sein de chaque nation. Nous construisons un modéle d'économie politique représentant une économie à deux pays où un accord sur le financement d'un bien collectif transnational doit être négocié entre les représentants des deux pays. Nous montrons que tout accord international implique des impôts plus élevés dans les deux pays que dans le cas d'une absence d'accord. Si un accord existe, il peut se trouver des perdants à l'accord dans chacun des pays. Si le processus de négociation suppose une contrainte sur les taux d'imposition, un accord peut ne pas être obtenu. Finalement, quand un accord est obtenu, il peut impliquer une délégation stratégique quand les électeurs médians dans les deux pays sont les vainqueurs de Condorcet : cette délégation est la résultante du conflit entre les électorats pour transférer le fardeau fiscal sur les contribuables de l'autre pays. Ainsi, le destin d'un accord international dépend des jeux politiques nationaux et des questions de redistribution dans les pays qu'il concerne.

Mots-clés: accords internationaux, négociations, délégation, vote.

JEL classification: D72, H77. 


\section{Introduction.}

The issue of whether countries should agree on international agreements, how to bargain for them and implement such agreements is a daily concern for governments and central to international affairs.

It is hard to overemphasize the importance of these agreements. Primary examples are international agreements on standards (health, telecommunications, patents), monetary unions, defense alliances, tax agreements, or international environmental agreements, to name a few. They are easily justified by means of the presence of cross-border externalities: Given the worldwide determinants of weather forecasting, an international agreement on the sharing of meteorological data seems quite adequate and in the interest of all.

But international negotiations sometimes fail or lead to agreements much less ambitious than originally envisioned. The modest outcome of the Copenhagen summit is a clear example of the difficulty to reach an international agreement on the global warming issue. The painful process of European union's institutional upgrading also exemplifies the difficulty of setting international agreements. Finally, the creation of the EMU proved to be a mixed political success as not all members of the European Union decided to join this monetary union. Of course, most international agreements do not reach such a fame. The United Nations Treaty series, by far the most comprehensive database on these agreements, contains over 34,000 agreements made by sovereign nations belonging to the U.N. since 1946. In 1999, 32,939 were bilateral. ${ }^{1}$ This series registers the "Agreement concerning financial cooperation on the Lake Volta Transport System", signed in 1980 between the Federal Republik of Germany and Ghana, as well as the 1967 "Outer Space multilateral agreement", forbiding the placement of weapons of mass destruction into orbit, onto celestial bodies or in outer space.

The outcome of a negotiation process towards the establishment of an international agreement (hereafter IA) depends on a few crucial features: the type of ties imposed on the agreement, the nature of the process through which the various countries negotiate an agreement, and last but not least, the calculus made by national electorates, when voters are diversely affected by the agreement and thus hold different views about its desirability. In particular, these structural features explain why some agreements are not reached and the international negotiation process may lead to a failure, that is the inability to establish some sort of cooperative effort. ${ }^{2}$

This amounts to say that distributive considerations cannot be neglected in the setting of an IA as any agreement involves taxes and public spending. Because a proposed agreement, or an expected one, leads to a different balance between

\footnotetext{
${ }^{1}$ According to the U.N. charter, "every treaty and every international agreement entered into by any Member of the United Nations after the present charter comes into force shall as soon as possible be registered with the Secretariat and published by it". The list of agreements can be found at http://www.un.org/Depts/Treaty/.

${ }^{2}$ Langlois and Langlois (2006) have modified the Rubinstein approach to bargaining and conclude that various international agreements, such as SALT and NAFTA, are consistent with their findings. However they only focus on the bargaining procedure without endogenizing the choice of the bargainers.
} 
losses and gains when agents are characterized by different levels of resources, it is diversely appreciated by the voters: some may be harmed and consequently vote against it, whereas some are net beneficiaries and support it. ${ }^{3}$ Thus distributive effects, associated to an international agreement, play a role through the political process.

However the existing theoretical literature on international agreements has largely neglected the political aspect of the negotiation process, linked to electoral considerations. ${ }^{4}$

In this paper we tackle the issue of the negotiation of international agreements in a political economy perspective, focusing on international agreements dealing with the provision of public goods. We deal solely with technological externalities, not pecuniary externalities. We do not address agreements on price restrictions or competitive issues, like international trade agreements or agreements on tariffs. This implies that trade liberalization rounds under the guidance of the WTO are out from the scope of the paper.

We set up a simple economic model with an international public good, financed by contributions from both countries. This good is funded through taxes, levied at the national level. ${ }^{5}$ There is an unequal income distribution in each country. These distributions may differ across countries. There is no international authority and therefore the two national governments are the relevant authorities to tackle the common issue.

We then specify a political process in which an IA is negotiated between delegates from the two countries, elected through a democratic process taking place in each country. We study two types of IA, involving different sets of constraints on the policies to be implemented: one imposes an equal tax rate provision in each country ("equal tax rate rule"), the other one imposes an equal gains provision ("equal gains rule").

The political process is formally a two-stage game. In the first stage, electorates in each country vote to elect their representative or "delegate" at the negotiation

\footnotetext{
${ }^{3}$ The way voters express their opinion depends of course on the electoral system in place.

${ }^{4}$ In general, IAs dealing with public goods have been studied by means of coalition theory and bargaining theory. This is particularly true for the case of environmental international agreements (Barrett, 2003). Currarini and Tulkens (2004) address the issue of environmental international agreements and hint at a political economy perspective, but they mainly develop a coalition formation approach. Buchholtz et al. (2005) show in the case of environmental international agreements how voters vote strategically in both countries, but assuming side-payments in the bargaining process, they assume away the divergent goals of delegates. As a result Alesina et al. (2005) study the impact of voting procedures within an international union where the various members have to reach a common decision by vote and do not address the bargaining of an IA. Rota-Graziosi (2009) is the closest to our setting. Contrarily to what is assumed here, he focuses on the ratification in each country of an IA, once it has been bargained. Moreover he does not address the impact of the inequality schedule on a tax distortive mechanism, which is the main focus of our analysis. International trade agreements have been extensively studied, including by political economy theoreticians. But we do not deal here with this kind of IAs.

${ }^{5}$ It would be formally equivalent to consider two national public goods which generate crossborder externalities.
} 
table. In the second stage, the two delegates meet, negotiate and may strike an agreement. If no agreement is reached, then the two delegates apply the non-cooperative policies of their choice.

With such an apparatus, we are able to prove that an IA involves higher taxes in both countries than non-cooperation. We also prove that there may exist losers to an IA in each country. The political process may fail to establish an IA, depending on the institutional constraint imposed on the negotiation process: this may happen in the case of an equal tax rate rule.

Assuming a simple majority rule, in the case of a successful negotiation process, leading to the establishment of an IA, there may be strategic delegation in the following sense: we determine sufficient conditions under which the Condorcet winner in at least one country is the median voter and chooses not to go to the negotiation table but send someone else as the country's delegate.

The plan of the paper is as follows. In the second section, we present our model of a two-country economy with an international public good, generating interjurisdictional externalities. Then, in Section 3, we define the political process through which international agreements are negotiated between the two countries. In section 4 , we focus on the possibility of international agreements and characterize the sets of feasible agreements in relation with the assumed political process. In the two following sections, we specifically explore the negotiation process, taking into consideration two types of institutional constraints to be satisfied by the international agreement. Section 7 concludes.

\section{A two-country economy with international pub- lic good.}

We consider a two-country world economy. In each country, there is a continuum of agents, diffenciated by income. We denote by $y_{i}$ the income of agent $i$. In Country $j, f_{j}(y)$ represents the population density of agents with income $y$. We denote by $y_{j}^{\min }$ and $y_{j}^{\max }$ respectively the minimal and maximal incomes in Country $j$. We set $\mathbf{C}_{j}=\left\{y ; f_{j}(y)>0\right\}=\left[y_{j}^{\min } ; y_{j}^{\max }\right]$

We get:

$$
N_{j}=\int_{y_{j}^{\min }}^{y_{j}^{\max }} f_{j}(y) d y
$$

where $N_{j}$ denotes the population in Country $j$.

In order to focus solely on the impact of the endowment distributions, we assume that total endowments are equal in both countries and normalized to 1, i.e. $\int_{y_{j}^{\min }}^{y_{\max }^{\max }} y f_{j}(y) d y=1$, for $j=1,2$. The median individual's income in country $j$ is denoted by $y_{m_{j}}$.

The individual utility of an agent $i$ with income $y_{i}$ depends both on her consumption of a private good, $c_{i}$, and on the provision of an international public good, shared by the two countries and financed through their contributions. 


$$
W_{i}=W\left(c_{i}, G\right)=c_{i}+G
$$

where $G$ denotes the utility derived from a "global" public good, assuming a linear separable utility in consumption and $G$.

Agents are taxed so as to finance this public good and taxation is proportional to income. Since incomes are exogenously given, as the provision of the public good depends on the tax rates applied in each country, $G$ depends on both tax rates:

$$
G=G\left(\tau_{1}, \tau_{2}\right)
$$

where $\tau_{j}$ denotes the tax rate applied in country $j . G($.$) is an additive and separable$ function, increasing in its two arguments. ${ }^{6}$ Both countries have a symmetric effect on the public good and therefore:

$$
G=H\left(\tau_{1}\right)+H\left(\tau_{2}\right) .
$$

$H(\tau)$ is assumed to be an increasing concave function of $\tau$. We assume in the following that the concave increasing function $H(\tau)$ is defined as such:

$$
\left.H(\tau)=\frac{\tau^{1-\theta}}{1-\theta}, \theta \in\right] 0 ;+\infty[, \theta \neq 1, H(\tau)=\ln \tau \text { for } \theta=1
$$

The concavity of $H(\tau)$ depends positively on $\theta$. If $\theta$ is bigger or equal to 1 , the absence of public good provision $(G=0)$ leads to a catastrophic situation as $W_{i}=-\infty$, for every $i$. On the other hand, if $\theta>1$, such an absence is not catastrophic as $W_{i}>0$, for every $i$, even when $G=0 .{ }^{7}$

Since taxation is proportional to income, we get for agent $i$ living in Country $j$ :

$$
c_{i}=\left(1-\tau_{j}\right) y_{i}
$$

Given the previous equations, her welfare can be rewritten as:

$$
\begin{aligned}
W\left(y_{i}, \tau_{j}, \tau_{-j}\right) & =y_{i}\left(1-\tau_{j}\right)+H\left(\tau_{j}\right)+H\left(\tau_{-j}\right) \\
& =F\left(y_{i}, \tau_{j}\right)+H\left(\tau_{-j}\right)
\end{aligned}
$$

where we set

$$
F(y, \tau)=y(1-\tau)+H(\tau)
$$

The present model is minimal but sufficient to emphasize the key ingredients of a political approach to IAs: each individual faces a trade-off between private consumption and the benefit from the international public good; in each country there is inequality so voters do have different views on this trade-off. As the global public good is shared by both countries, this provides an argument in favor of some form of cooperation, through an IA.

Each agent in any country wants to tax and spend for the public good because her individual welfare is directly affected by its provision: the higher this provision the higher the $G$ component of welfare. ${ }^{8}$

\footnotetext{
${ }^{6}$ Recall that in each country total endowment is equal to 1.

${ }^{7} \mathrm{~A}$ more general specification would be $H(\tau)=b \cdot \frac{\tau^{1-\theta}}{1-\theta}$. We assume $b=1$ for simplicity reasons.

${ }^{8}$ In the sequel, we refer to an agent by means of her income, and we write "agent $y_{i}$ ".
} 


\section{The Politics of International agreements (IA).}

The logic of an IA between two sovereign countries is to cooperate so as to improve the situation of each country, as seen by its policymaker, compared to the situation of no-cooperation. There must be unanimity upon an IA between the two national policymakers: If one policymaker, exerting national sovereignty, opposes a proposed international scheme for the funding of the public good, it cannot be enforced in her country. In our setting, a country's policymaker is its delegate.

To formalize this logic, we set up a game with the following sequential development:

1. The election stage. First, each national constituency decides on who will participate on the negotiation of the IA on its behalf. This decision may be taken by means of different political mechanisms. In the following, when we specifically study the political process used to choose a delegate, we shall assume that this choice is done by means of a simple majority vote. A country delegate is restricted to belong to the population of this country.

2. The negotiation stage. The two national delegates are characterized by their incomes $\widetilde{y}_{1}$ and $\widetilde{y}_{2}$. When the negotiators meet, they negotiate over the tax rates to apply in each country. Moreover the IA is constrained to follow a given rule which is exogenously given and is defined below. If there is no agreement, the non-cooperative tax rates preferred by the two delegates are implemented.

There is no uncertainty. As voters are assumed to be rational agents, they perfectly calculate the final outcome of their decisions.

Given the structural characteristics of the two constituencies and obviously the differing benefits obtained from the public good, whether an IA can be attained depends on the political process through which such an IA is investigated. In particular, it is common to observe that negotiators are given some constraints on how to negotiate, which limit their latitude at the negotiation table. These may be constraining rules on the instruments and/or the objectives of the negotiation process under which negotiators look for an agreement. As we want to investigate the impact of differents constraints on the obtention and the characteristics of an IA, we consider 2 types of constraining rules.

R1 Equal tax rate rule: an agreement must simultaneously be feasible, that is acceptable by both country delegates, and satisfy the constraint that a common tax rate $\left(\tau_{1}=\tau_{2}=\tau\right)$ be applied by each country.

R2 Equal gains rule: an agreement must be feasible and satisfy the constraint that both delegates draw equal gains from the IA.

The first one, R1, is an example of a constraint put on the use of instruments, whereas the second one, R2, is an example of a constraint put on the benefits. 
Given our political economy perspective, rules can be justified through politically feasibility considerations. ${ }^{9}$ A rule is a restriction on an agreement or an outcome which renders this agreement or outcome politically acceptable. In this view, as far as instruments are concerned, voters in each country may impose at some constitutional level that the two countries share the same effort with respect to the common good. This corresponds to an equality in the instruments fixed by the negotiators, that is rule R1. Alternatively, it may seem "fair" to the voters in one country that their country obtains a benefit from the agreement, proportionate to the benefit obtained by the other country. The second rule R2 is a simple example, adapted to our framework, of such a constraint.

Other rules could of course be studied. We restrict to these two rules as they are examples of rules imposed either on the use of policy instruments or on the national benefits linked to the agreement. ${ }^{10}$

We need to specify how the delegates bargain at the negotiation table. We shall assume that delegates bargain according to the Nash-bargaining solution. ${ }^{11}$ Finally, any negotiation process between delegates requires the definition of the non-cooperative equilibrium attached to these delegates. Formally, no-cooperation is defined as follows. Each delegate sets the tax rate to be applied to his country non-cooperatively, taking as given the other country's policy decision. That is, the optimal tax rate that agent $i$, characterized by income $y_{i}$, living in country $j$, would like to prevail is defined as:

$$
\tau^{*}\left(y_{i}\right)=\arg \max _{\tau_{j}} W\left(y_{i}, \tau_{j}, \tau_{-j}\right)=\arg \max _{\tau_{j}} F\left(y_{i}, \tau_{j}\right)
$$

Her response depends on her endowment, as the tax rate generates the funding used for the provision of the public good. We find easily that $\tau^{*}\left(y_{i}\right)=\left(y_{i}\right)^{-1 / \theta}$ : the lower the value of $y_{i}$, the more agent $i$ accepts a high tax rate so as to get a higher provision of the public good. The parameter $\theta$ determines the relative benefits associated with the public good for any agent. The higher $\theta$, the larger the tax rate, and therefore the part of national income devoted to the public good, wished by any individual.

The non-cooperative equilibrium, $\left(\tau_{1}^{*}, \tau_{2}^{*}\right)$, does not depend on the type of rule being followed in the negotiation process. In the following proposition, we characterize such an equilibrium.

Proposition 1 There exists a unique non-cooperative equilibrium $\left(\tau_{1}^{*}, \tau_{2}^{*}\right)$ where $\tau_{j}^{*}$ refers to the tax rate wished by the delegate $\widetilde{y}_{j}$ in Country $j$ and is equal to:

$$
\tau_{j}^{*}=\arg \max _{\tau_{j}} F\left(\widetilde{y}_{j}, \tau_{j}\right) \text { and } \widetilde{y}_{j}=H^{\prime}\left(\tau_{j}^{*}\right)=\left(\tau_{j}^{*}\right)^{-\theta}
$$

$\tau_{j}^{*}$ is a decreasing function of $\widetilde{y}_{j}$.

\footnotetext{
${ }^{9}$ There are many ways to legitimate the imposition of rules in a setting with multiple players. They are often justified by some incentive considerations or for time-inconsistency reasons. Here, as we do not consider any asymmetric information problem and our sequential game is neatly defined, these considerations do not apply.

${ }^{10}$ Given the assumed equality in power and the absence of size effects, we concentrate on equal rules. Our results generalize to other linear rules at the expense of clarity.

${ }^{11}$ See Muthoo, 1999, for a detailed presentation of the Nash-bargaining process.
} 


\section{Proof See Appendix A.}

Notice that $\tau_{j}^{*}=\tau^{*}\left(\widetilde{y}_{j}\right)$ is independent from $\tau_{-j}^{*}$. This dominant strategy characteristics is due to the assumption of additivity of $G$. The marginal impact of $\tau_{j}$ on $j$ 's welfare does not depend on $\tau_{-j} .{ }^{12}$ Finally, given the positivity of $\theta$, the tax rate desired by an agent is a decreasing function of her income. The poor are in favor of the public good as they are less sensitive to the proportional tax levied on them than the rich. This solution will be used as a benchmark for the assessment of IAs. Indeed, the status quo in the Nash-bargaining between two given delegates is assumed to be the non-cooperative equilibrium for these two delegates.

For an agent $i$, in country $j$, the gain derived from an IA, setting a pair of tax rates $\left(\tau_{1}, \tau_{2}\right)$, with respect to non-cooperation is:

$$
\begin{aligned}
\Gamma_{j}\left(y_{i}, \tau_{1}, \tau_{2}, \tau_{1}^{*}, \tau_{2}^{*}\right) & =W\left(y_{i}, \tau_{j}, \tau_{-j}\right)-W\left(y_{i}, \tau_{j}^{*}, \tau_{-j}^{*}\right) \\
& =\left[H\left(\tau_{1}\right)+H\left(\tau_{2}\right)-H\left(\tau_{1}^{*}\right)-H\left(\tau_{2}^{*}\right)\right]-y_{i}\left(\tau_{j}-\tau_{j}^{*}\right) .
\end{aligned}
$$

The gain drawn by a given agent in a given country from an IA negotiated between two delegates is computed relative to the situation which would prevail, had this precise agreement not been obtained, that is the non-cooperative equilibrium obtained if the two delegates do not succeed in setting an agreement. Hence this gain depends first on her income $y_{i}$, that is the tax base upon which national taxes are levied, second on the tax pair related to the agreement, $\left(\tau_{j}, \tau_{-j}\right)$, and the tax pair related to the no-agreement situation, $\left(\tau_{j}^{*}, \tau_{-j}^{*}\right)$. This comes directly from the assumption that the delegates have control both on the reaching of an agreement, and on the non-cooperation equilibrium. This gain is the sum of two components. The first one, $\left[H\left(\tau_{1}\right)+H\left(\tau_{2}\right)-H\left(\tau_{1}^{*}\right)-H\left(\tau_{2}^{*}\right)\right]$, is identical for any agent living in any of the two countries: this comes from the assumption that the public good is common to both countries and does not generate differentiated benefits. The second one, $-y_{i}\left(\tau_{j}-\tau_{j}^{*}\right)$, is specific to an agent, depending on his income, and the tax rates enforced in his country. Agents dislike an increase in taxation linked to an international agreement (as it represents a reduction in private consumption) and the more so the richer they are.

Given these notations, the "equal gains rule" corresponds to an IA specifying a pair of tax rates $\left(\tau_{1}, \tau_{2}\right)$ such that $\Gamma_{1}\left(\widetilde{y}_{1}, \tau_{1}, \tau_{2}, \tau_{1}^{*}, \tau_{2}^{*}\right)=\Gamma_{2}\left(\widetilde{y}_{2}, \tau_{1}, \tau_{2}, \tau_{1}^{*}, \tau_{2}^{*}\right)$.

As we shall see, the set of constraints which defines the type of agreement and is imposed upon the negotiators, may or may not hamper their capacity to reach an agreement, and therefore affects the individual gains drawn from an agreement.

\footnotetext{
${ }^{12}$ This assumption could be relaxed at the expense of simplicity. As we are interested in the impact of an IA relative to the case of non-cooperation, more than about the properties of noncooperative policies with respect to the public good, this assumption suffices.
} 


\section{Feasible agreements.}

We first want to check that there is scope for negotiating over the public good. That is, we want to see whether, given a pair of delegates $\left(\widetilde{y}_{1}, \widetilde{y}_{1}\right)$, there are pairs of tax rates such that if chosen, they generate positive gains for each of the delegates. Formally we first give two definitions:

Definition 1 The set of feasible agreements is

$$
\mathcal{T}\left(\widetilde{y}_{1}, \widetilde{y}_{2}\right)=\left\{\left(\tau_{1}, \tau_{2}\right) ; \Gamma_{1}\left(\widetilde{y}_{1}, \tau_{1}, \tau_{2}, \tau_{1}^{*}, \tau_{2}^{*}\right) \geq 0 \text { and } \Gamma_{2}\left(\widetilde{y}_{2}, \tau_{1}, \tau_{2}, \tau_{1}^{*}, \tau_{2}^{*}\right) \geq 0\right\}
$$

Definition 2 The set of strongly feasible agreements is

$$
\mathcal{T}_{+}\left(\widetilde{y}_{1}, \widetilde{y}_{2}\right)=\left\{\left(\tau_{1}, \tau_{2}\right) ; \Gamma_{1}\left(\widetilde{y}_{1}, \tau_{1}, \tau_{2}, \tau_{1}^{*}, \tau_{2}^{*}\right)>0 \text { and } \Gamma_{2}\left(\widetilde{y}_{2}, \tau_{1}, \tau_{2}, \tau_{1}^{*}, \tau_{2}^{*}\right)>0\right\} \text {. }
$$

The set of feasible agreements depends on the pair of delegates involved in the negotiating process. This comes from the critical role played by delegates: first, they bargain for themselves, having in mind their own gains without any altruistic motive; second, in case of no-agreement, they are the ones who select, for their own country, the non-cooperation tax rates. The set of strongly feasible agreements includes pairs of rates generating a strictly positive gain for each delegate.

The equilibrium of a game leading to an IA must belong to the set of feasible agreements corresponding to the pair of delegates characterizing this equilibrium. This amounts to say that the set of feasible agreements is contingent on the pair of individuals who bargain over the agreement and varies with this pair. In other words, at the election stage, voters in each country need to have in mind that they don't choose a delegate bargaining with her counterpart over a fixed set of possibilities, but that this set of possible outcomes itself is part of the equilibrium of the game and varies with the pair of delegates. This proves how complex are the strategies of the voters when dealing with IAs.

Given these definitions, we first prove the following:

Proposition 2 For any given $\left(\widetilde{y}_{1}, \widetilde{y}_{2}\right), \mathcal{T}\left(\widetilde{y}_{1}, \widetilde{y}_{2}\right)$ is a convex subset of $\left[\tau_{1}^{*} ; 1\right] \times\left[\tau_{2}^{*} ; 1\right]$ with $\left(\tau_{1}^{*}, \tau_{2}^{*}\right) \in \mathcal{T}\left(\widetilde{y}_{1}, \widetilde{y}_{2}\right)$. Moreover, $\mathcal{T}_{+}\left(\widetilde{y}_{1}, \widetilde{y}_{2}\right)$ is non-empty.

\section{Proof See Appendix B.}

The set of feasible agreements is delimited by two curves, as shown in Figure 1. The curve $\left\{\Gamma_{1}=0\right\}$ corresponds to the set of tax rates such that the delegate of Country 1 makes no gain with respect to the non-cooperative equilibrium $\left(\tau_{1}^{*}, \tau_{2}^{*}\right)$; the curve $\left\{\Gamma_{2}=0\right\}$ is similarly defined for the delegate of Country 2. These two curves necessarily intersect at $\left(\tau_{1}^{*}, \tau_{2}^{*}\right)$. One curve is concave, the other convex because of the assumptions made on the utility function. The set of feasible agreements is convex.

An important characteristics of $\mathcal{T}\left(\widetilde{y}_{1}, \widetilde{y}_{2}\right)$ is that it implies more taxation in both countries compared to what we get under no-cooperation. This can be explained 


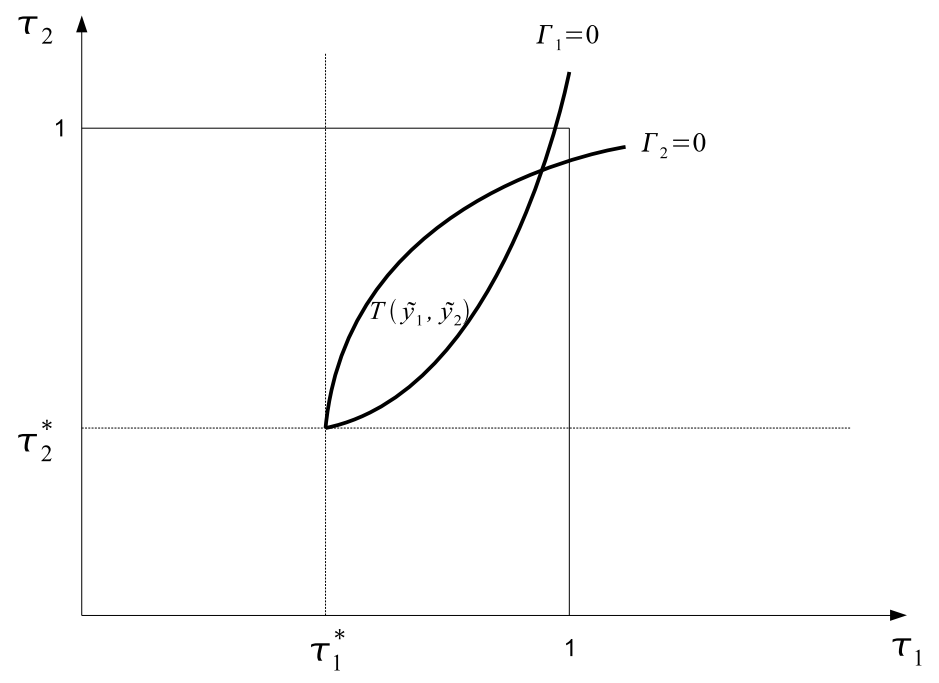

Figure 1: Set of reachable agreements $\mathcal{T}\left(\widetilde{y}_{1}, \widetilde{y}_{2}\right)$

as follows. There are positive externalities between the two countries which explain why the non-cooperation solution is suboptimal from the perspective of the two delegates. An IA implies positive gains in both countries. Country $j$ gains from an agreement if for a given tax rate $\tau_{j}$, the other country increases its taxing effort, that is its funding of the common public good. Given that this must be true for both countries, an IA implies more taxation in both countries.

If we impose constraints on an IA, such as the rules R1 and R2, these restrictions will imply another set of feasible agreements, actually to be a subset of the set we have just defined. We shall develop on this point in the sequel.

The notion of a (strongly) feasible agreement suffices us to show that the benefits drawn from a feasible IA by individuals are differentiated according to their personal positions, that is their incomes. In particular, it may happen that a feasible IA generates losers as well as beneficiaries as we can prove the following:

Proposition 3 For any given strongly feasible agreement $\left(\tau_{1}, \tau_{2}\right)$, linked to a couple of delegates $\left(\widetilde{y}_{1} ; \widetilde{y}_{2}\right)$, there exist $\left.\widehat{y}_{1} \in\right] \widetilde{y}_{1},+\infty\left[\right.$ and $\left.\widehat{y}_{2} \in\right] \widetilde{y}_{2},+\infty[$, such that

$$
\text { for } i \in \mathbf{C}_{j} \text {, we have } y_{i}>\widehat{y}_{j} \Leftrightarrow \Gamma_{j}\left(y_{i}, \tau_{1}, \tau_{2}, \tau_{1}^{*}, \tau_{2}^{*}\right)<0
$$

The threshold value $\widehat{y}_{j}$ is a decreasing function of $\widetilde{y}_{j}$, and an increasing function of $\widetilde{y}_{-j}$.

\section{Proof See Appendix C.}

Here we consider a given strongly feasible agreement $\left(\tau_{1}, \tau_{2}\right)$. Using $(9)$, it is immediate to remark that, as the term associated with the global public good is independent from individual income, and the second term, linked to taxation, is 
monotonously decreasing with individual income, the individual gain $\Gamma_{i}$ is decreasing with $y_{i}$. The richer is an agent, the lower the gain he gets from an agreement $\left(\tau_{1}, \tau_{2}\right)$, as he increasingly resents the increase in taxes involved with the IA. As the agreement considered is strongly feasible, it generates positive gains for the two delegates $\widetilde{y}_{1}$ and $\widetilde{y}_{2}$ and hence, it is also true for any agent who is poorer that his country's delegate. On the contrary, for an agent arbitrarily rich, the gain is negative (it is a loss) and arbitrarily large in absolute value. This explains why there is a threshold value $\widehat{y}_{j}>\widetilde{y}_{j}$ for which the gain is null.

If the delegate of Country $-j$ gets richer, he taxes less in the non-cooperative equilibrium. Hence the gain drawn from an agreement stating a given pair of tax rates by any agent in Country $j$ increases. Therefore the threshold income in $j$ is an increasing function of the income of the delegate chosen in $-j$.

On the other hand, for a given pair of tax rates $\left(\tau_{1}, \tau_{2}\right)$ obtained through an IA, a richer delegate in Country $j$ would choose a lower non-cooperative tax rate. This would have two effects on Country $j$ 's residents. First, such a decrease has a taxing impact: less taxation ceteris paribus increases private consumption for all residents in Country $j$, which reduces the gain drawn from the pair $\left(\tau_{1}, \tau_{2}\right)$. Second, it has a public good provision effect: it reduces the amount of public good non-cooperatively provided in Country $j$, which harms the residents in this country, and therefore augments the gain drawn from $\left(\tau_{1}, \tau_{2}\right)$. The specification of the utility function is such that the first effect dominates the second one. Therefore, since the noncooperative tax rate is a decreasing function of the delegate's income, the threshold value in $j$ is a decreasing function of the income value of the delegate chosen in $j$.

This proposition makes explicit the distributive effects of an IA across nations formed of differentiated agents. As their personal situations differ (here because of income distribution), different agents draw different gains from a given IA. When the two delegates care solely about their own welfare (admittedly an extreme case, but which could be relaxed without modifying this qualitative result), an IA generating gains for these delegates and therefore for agents similar to them may well generate losses to some agents, if they are sufficiently richer than their country's delegate.

\section{The equal tax rate rule.}

Let us now turn to the study of particular rules imposed on IAs. In general, negotiators of an IA do not have total freedom but are subjected to rules that an IA must fulfill. These rules may come from constitutional and legal considerations, customs, ethical considerations unanimously shared by the populations of the two countries, and so on. We shall not investigate their origin. Indeed, we shall solely study two such rules, in order to show that they generate strikingly different properties attached to an IA. The first one, to be considered in this section, imposes that delegates must bargain over an IA which sets a unique and common tax rate upon both constituencies (R1).

As we said earlier, imposing this rule on IAs implies a narrower set of feasible agreements. Hence we use the following: 
Definition 3 The set of feasible agreements under rule $R 1$ is

$$
\mathcal{T}^{1}\left(\widetilde{y}_{1}, \widetilde{y}_{2}\right)=\mathcal{T}\left(\widetilde{y}_{1}, \widetilde{y}_{2}\right) \cap \Delta
$$

where $\Delta=\left\{\left(\tau_{1}, \tau_{2}\right) \mid \tau_{1}=\tau_{2}\right\}$.

Definition 4 The set of strongly feasible agreements under rule R1 is

$$
\mathcal{T}_{+}^{1}\left(\widetilde{y}_{1}, \widetilde{y}_{2}\right)=\mathcal{T}_{+}\left(\widetilde{y}_{1}, \widetilde{y}_{2}\right) \cap \Delta
$$

These definitions immediately derive from the previous ones on sets of feasible agreements.

\subsection{The (non-)existence of IA.}

The first issue we encounter is whether international agreements are feasible under the $\mathrm{R} 1$ rule. If the set $\mathcal{T}_{+}^{1}\left(\widetilde{y}_{1}, \widetilde{y}_{2}\right)$ is empty, there exists no agreement which can be obtained by these two delegates which could simultaneously improve their situations compared to the no-cooperative equilibrium. We prove that $\mathcal{T}_{+}^{1}\left(\widetilde{y}_{1}, \widetilde{y}_{2}\right)$ may be empty in the following proposition:

Proposition $4 \mathcal{T}^{1}\left(\widetilde{y}_{1}, \widetilde{y}_{2}\right)$ may be empty. More precisely: Let $b(\theta)=\left(\theta\left(2^{1 / \theta}-1\right)\right)^{\theta /(1-\theta)}>1$ for $\theta \neq 1$ and $b(1)=\frac{4}{e}$.

Defining the cone $\mathcal{C}(\theta)=\left\{\left(\widetilde{y}_{1}, \widetilde{y}_{2}\right) ; \frac{\widetilde{y}_{2}}{\widetilde{y}_{1}} \in\left[\frac{1}{b(\theta)} ; b(\theta)\right]\right\}$ we have:

- if $\left(\widetilde{y}_{1}, \widetilde{y}_{2}\right) \in \mathcal{C}(\theta)$, there exists an equal rate agreement;

- if $\widetilde{y}_{j}>b(\theta) \widetilde{y}_{-j}$, then the country $j$ delegate rejects any equal rate agreement.

Proof: See Appendix D.

First, there may not exist a feasible agreement under R1, for a given pair of delegates. That is, this pair is unable to find a tax rate, to be applied in both countries, which maximizes the product of their gains. At least, one of them prefers the non-cooperative solution to any tax rate jointly enforced by both countries. This can be understood in the following way. Remark that if both delegates are characterized by the same amount of income, it is easy for them to find a solution. It is the rate which internalizes the externality generated by the financing of the common good in one country and impacting on the welfare of the delegate from the other country. But as soon as the two delegates have different incomes, their interests start diverging.

The poorer delegate is in favor of a higher tax rate, whereas the richer one is in favor of a lower one. Hence a common tax is a way for the poor to extract more income from the rich for the public good. The poorer delegate pushes for more tax, with respect to the no-agreement case, the richer delegate tends to resist this push, even though an agreement leads to an increase in the provision of the public good, because a disproportionate part of its funding is borne upon him. If their incomes 


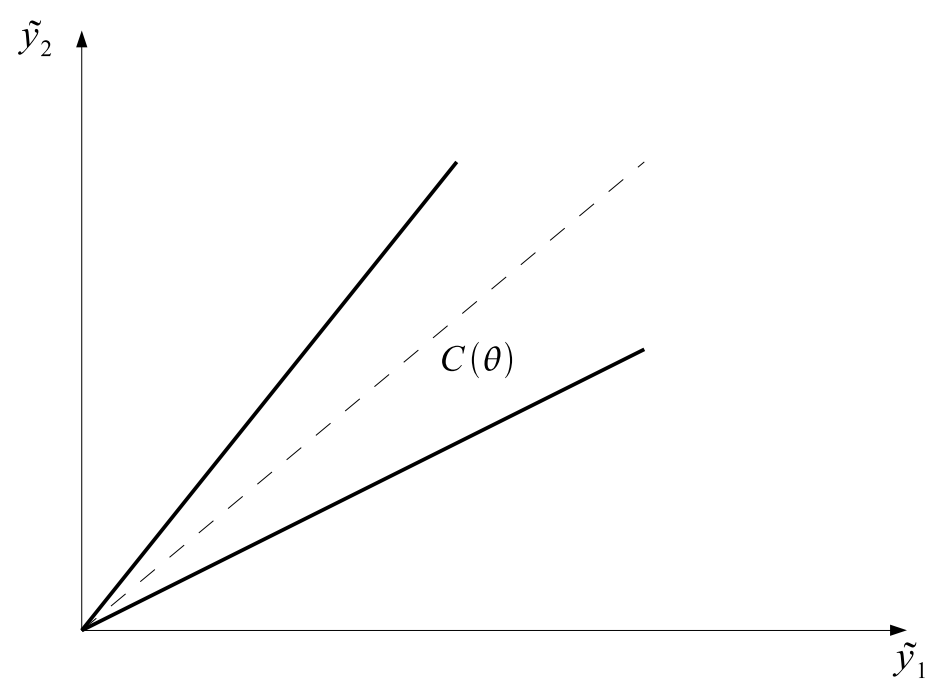

Figure 2: Cone $\mathcal{C}(\theta)$

are too far apart, and therefore their interests in the common good largely diverge, the rich delegate will prefer the no-cooperation equilibrium to any common tax rate imposed on both countries. The gain from the internalization of the externality through the public good does not compensate for the loss from having to suffer a too high tax rate, with respect to the no-cooperation tax rate that the delegate can impose on his country.

The result that the two incomes must not be too far apart is expressed by the fact that the pair of delegates' incomes must belong to a cone $\mathcal{C}(\theta)$. For a given value of $\theta$, given the poor delegate's income, there is a critical value for the rich delegate's income such that above it, the rich delegate rejects any agreement as it implies that he support a disproportionate share of the tax burden. If the poor delegate's income is very low, at a given common tax rate, she will contribute very little to the public good; consequently, the threshold value associated with this low level of income is itself very low as the richer delegate is sensitive to the contribution of the poorer delegate compared to his own. Given the symmetry assumption (see Equation (3)), this explains the symmetrical cone.

The rich delegate may come from either country. That is why the delegate from either country may reject an agreement. In other words, inequality between the two delegates plays a critical role not only in the shaping of an IA, but on its very existence.

\subsection{Bargaining.}

We shall now suppose that IAs meeting the restriction R1 exist. More precisely, we assume that the pair of delegates $\left(\widetilde{y}_{1}, \widetilde{y}_{2}\right) \in \mathcal{C}(\theta)$, and therefore $\mathcal{T}^{1}\left(\widetilde{y}_{1}, \widetilde{y}_{2}\right)$ is not empty. Hence there exists a tax rate $\tau^{r}$ such that $\left(\tau^{r}, \tau^{r}\right)$ belongs to $\mathcal{T}^{1}\left(\widetilde{y}_{1}, \widetilde{y}_{2}\right)$ and 
is the solution of the bargaining process taking place between the two delegates. In other words, given a pair of delegates, we focus on the characteristics of the IA which results from their bargaining. Without loss of generality, we assume that the delegate from Country 2 is richer than the delegate from Country $1\left(\widetilde{y}_{1}<\widetilde{y}_{2}\right)$. As delegates adopt the Nash-bargaining solution, the tax rate $\tau^{r}$ maximizes the product of the gains of the two delegates:

$$
\tau^{r}=\arg \max _{\tau ;(\tau, \tau) \in \mathcal{T}^{1}\left(\widetilde{y}_{1}, \widetilde{y}_{2}\right)} \gamma(\tau)
$$

where

$$
\gamma(\tau)=\Gamma_{1}\left(\widetilde{y}_{1}, \tau, \tau, \tau_{1}^{*}, \tau_{2}^{*}\right) \times \Gamma_{2}\left(\widetilde{y}_{2}, \tau, \tau, \tau_{1}^{*}, \tau_{2}^{*}\right)
$$

We are able to offer the following proposition about the characteristics of the agreed IA under R1:

Proposition 5 A Nash-bargained equal rate IA is such that, on the set $\left\{\left(\widetilde{y}_{1} ; \widetilde{y}_{2}\right) ; \widetilde{y}_{1}<\right.$ $\left.\widetilde{y}_{2}\right\}, \tau^{r}$ is a decreasing function of $\widetilde{y}_{2}$, and $\tau^{r}$ is an ambiguous function of $\widetilde{y}_{1}$.

\section{Proof See Appendix E.}

When the incomes of the two delegates get closer, their objectives become more congruent. In the limit, if both delegates happen to have the same income, their interest will be identical, and both of them will aim at the same tax rate: there will be no net transfers between them through the common tax rate. But as we have just seen, if they are far apart, the richer delegate will obtain lower benefit from the agreement. If they are too far apart, there is no agreement.

In this perspective, an agreement under the constraint of equal tax rates, depends on two features:

1. the absolute levels of delegate's income, as a richer delegate favors a lower (common) tax rate.

2. the discrepancy between the two delegate's incomes.

For the richer delegate $\left(\widetilde{y}_{2}\right)$, if he gets richer, two effects work in the same direction: his distaste of taxation increases both because he gets richer and relatively richer than $\widetilde{y}_{1}$. Hence he unequivocally bargains for a lower common tax rate. However for the poorer delegate $\left(\widetilde{y}_{1}\right)$, these two effects work in opposite direction: if she gets richer, her distaste of taxation increases, but her interests become more congruent with the other delegate as there is less imbalance in the financing of the international public good. If the second effect dominates the first one, this may lead to an IA specifying a higher common tax rate. 


\subsection{Delegating.}

Now we turn to the election stage of the delegates so as to complete the study of the equilibrium of the extensive game when $\mathrm{R} 1$ is imposed on the negotiation process. There are two political issues in this game between multiple agents involved in the bargaining over a common interest. The first issue is about the voting pattern taking place in each country: What are the respective influences of the various voters? How the elected delegate in the partner country influences the voting pattern? In particular, given a political decision rule, there may exist a decisive voter, who is critical in selecting the delegate: can he be identified? The second issue is the identity of the delegate. In particular, it may be that the decisive voter (if he exists) prefers not to go personally to the negotiation table, but send another individual, better capable of defending the decisive voter's interest, even if he bargains for himself, without any altruistic motive. The latter case exhibits "strategic delegation".

In order to explore the election stage, we restrict our attention to the case where the election of a delegate in one country is done according a simple majority rule. Up to now, all our results were compatible with many different political schemes for choosing national delegates. The issue of the political equilibrium leading to the choice of delegates is complex because there are many possible outcomes for this game. Formally, both delegates chosen by the electorates may or may not belong to the cone $\mathcal{C}(\theta)$, or one may belong to the cone and not the other. Given the sequential game we study, it is not easy to find an equilibrium in any situation. Of course, the adding of additional stages in case of deadlocks would allow us to do just that. But this is beyond the scope of this paper. Therefore, in this subsection, we explore a special case where any agent in Country 2 is richer than any agent in Country 1. ${ }^{13}$ That is, we make the following assumption:

$$
\mathbf{H}: y_{1}^{\max }<y_{2}^{\min }
$$

This assumption allows us to stress the importance of "between-country" inequality. We use the ratio $\frac{y_{2}^{\min }}{y_{1}^{\max }}$ as a rough measure of this inequality: the higher this ratio, the higher the difference between individual incomes for any pair of agents belonging to different countries. Under this assumption, we can prove that the two cases of strategic delegation and no strategic delegation may happen when delegates bargain for an equal tax rate international agreement.

First, we offer the following

Proposition 6 Under $H$, if $\frac{y_{2}^{\min }}{y_{1}^{\max }}>b(\theta)$, there is no agreement. Under the simple majority rule, in each country the median voter is the Condorcet winner and there is no strategic delegation in both countries.

\footnotetext{
${ }^{13}$ Given our assumption of equal aggregate endowments, this implies that Country 1 is more populated than Country 2.
} 


\section{Proof See Appendix F.}

In this proposition, we first show that strategic delegation may not happen. We investigate a special case, admittedly restrictive, where no pair of agents delegated by the two countries is able to reach an international agreement because of a large between-country inequality: any pair of potential delegates is characterized by a large difference in individual incomes, and therefore the individual interests of any pair of delegates are too far apart. Given that each agent in any country has a preferred policy which is a dominant strategy, the decision taken in the other country has no influence on the choice of the delegate. Therefore any agent would prefer to be at the negotiation table: the impossibility of an agreement would then lead to a no-agreement solution in which his own preferred non-cooperative tax rate would be imposed. As the preferred tax rate varies unambiguously with individual income, no agent is able to maximize the welfare of agent $i$, other than $i$ herself. Hence if under a given political rule, $i$ happens to be the Condorcet winner, she chooses to delegate herself to the negotiation table: there is no strategic delegation.

For this precise reason, under a simple majority electoral rule, the median voter theorem applies and the median voter is the Condorcet winner.

Now we prove that strategic delegation may happen under different circumstances. We get the following

Proposition 7 Under $H$, if $1<\frac{y_{2}^{\max }}{y_{1}^{\min }}<b(\theta)$, there is an agreement. Under the simple majority rule, in Country 2, the median voter is a Condorcet winner and there is strategic delegation, as the chosen delegate is richer than the median voter.

\section{Proof See Appendix G.}

There is strategic delegation in the following sense. Given this assumption, it is immediate that $y_{m_{2}}>\widetilde{y}_{1}$ and $\widetilde{y}_{2}>\widetilde{y}_{1}, \forall \widetilde{y}_{1} \in \mathbf{C}_{1}$.

Given the second set of inequality, and the equal tax rate rule, the marginal gain associated with an increase in $\tau^{r}$, for $\widetilde{y}_{2}$, is negative and it will be lower the richer is $\widetilde{y}_{2}$. Hence the agreed common tax rate will be decreasing in the income of the delegate from Country 2 for any delegate chosen in Country 1.

Given the first inequality $\left(y_{m_{2}}>\widetilde{y}_{1}\right)$, the median voter in Country 2 would prefer a lower tax rate than the one obtained through bargaining with country 1's delegate $\widetilde{y}_{1}$. Since the agreed common tax rate is unambiguously decreasing in $\widetilde{y}_{2}$, by choosing a sufficiently rich delegate, the median voter in Country 2 is able to get closer to her preferred tax rate. Hence she delegates strategically.

Finally, in the case of a common tax rate, the individual preferences in Country 2 are single-peaked. And thus the median voter theorem applies: the median voter is the Condorcet winner in this country.

The same results cannot be proven for Country 1 . This is due to the ambiguity we highlighted in Proposition 5: it may happen that, given the income distributions in both countries, facing a given delegate from Country 2, some poorer agents in Country 1 are in favor of a lower common tax rate than richer agents. 


\section{The equal gains rule.}

As we have just seen, imposing a restriction on the negotiation process, such as a common tax policy, may lead to the impossibility of reaching any agreement at the negotiation table. This impossibility result comes from the fact that the two delegates may be so far apart, and their interests so different that they cannot agree on a common tax rate. Imposing that the two delegates must make an equal gain is a way to attempt to reconcile the two delegates with the bargaining process. What are the properties and consequences of such a rule?

In order to answer these questions, we shall follow the same logic as in the case of the common tax rate rule. First we give the following

Definition 5 The set of feasible agreements under rule $R 2$ is

$$
\mathcal{T}^{2}\left(\widetilde{y}_{1}, \widetilde{y}_{2}\right)=\mathcal{T}\left(\widetilde{y}_{1}, \widetilde{y}_{2}\right) \cap D
$$

where $D=\left\{\left(\tau_{1}, \tau_{2}\right) \mid \Gamma_{1}\left(\widetilde{y}_{1}, \tau_{1}, \tau_{2}, \tau_{1}^{*}, \tau_{2}^{*}\right)=\Gamma_{2}\left(\widetilde{y}_{2}, \tau_{1}, \tau_{2}, \tau_{1}^{*}, \tau_{2}^{*}\right)\right\}$.

Definition 6 The set of strongly feasible agreements under rule R2 is

$$
\mathcal{T}_{+}^{2}\left(\widetilde{y}_{1}, \widetilde{y}_{2}\right)=\mathcal{T}_{+}\left(\widetilde{y}_{1}, \widetilde{y}_{2}\right) \cap D
$$

These definitions are similar to definitions 3 and 4 .

\subsection{Existence of IA.}

First we investigate the possibility for two delegates to find a pair of tax rates which generates the same gains for both, relative to their welfares achieved in the no-cooperation solution. Assuming the two delegates to be $\left(\widetilde{y}_{1}, \widetilde{y}_{2}\right)$, we prove the following

Proposition $8 \mathcal{T}_{+}^{2}\left(\widetilde{y}_{1}, \widetilde{y}_{2}\right)$ is non-empty.

Proof See Appendix H.

According to this proposition, for any pair of delegates $\left(\widetilde{y}_{1}, \widetilde{y}_{2}\right)$, pairs of taxes $\left(\tau_{1}, \tau_{2}\right)$ exist which satisfy the request of equal positive gains for both delegates. In other words, an international agreement which represents a positive gain for both delegates upon the no-agreement situation, is always feasible. The existence of an IA comes from the fact the equal gains requirement limits the attempt by the poorer delegate to pressure the richer delegate and make him finance a sufficiently large portion of the provision of the common public good. Such a requirement amounts to search for a "win-win" solution which dramatically reduces the conflict of interest between the two delegates.

This is made possible because we do not impose minimal values to the gain to be drawn from an IA. Consequently $\left(\tau_{1}, \tau_{2}\right)$ may be arbitrarily close to $\left(\tau_{1}^{*}, \tau_{2}^{*}\right)$. Even when the incomes of the two delegates are way apart, and therefore their ideal rates 
widely divergent, they may find slight increases from the no-cooperation rates which allow them to capture some of the positive external effect coming from higher tax rates. If we imposed that the equal gains be above a given minimal level, we would find that for some $\left(\widetilde{y}_{1}, \widetilde{y}_{2}\right)$, the set of strongly feasible agreements is empty.

\subsection{Bargaining.}

Given that the set of strongly feasible agreements under R2 is non-empty, there is one IA which maximizes the common gain drawn from it. What are the properties of a such an IA? The pair of tax rates $\left(\tau_{1}^{g}, \tau_{2}^{g}\right)$ maximizes the product of the gains of the two delegates:

$$
\begin{gathered}
\left(\tau_{1}^{g}, \tau_{2}^{g}\right)=\arg \max _{\left(\tau_{1}, \tau_{2}\right) ;\left(\tau_{1}, \tau_{2}\right) \in \mathcal{T}^{2}\left(\widetilde{y}_{1}, \widetilde{y}_{2}\right)} \Gamma_{1}\left(\widetilde{y}_{1}, \tau_{1}, \tau_{2}, \tau_{1}^{*}, \tau_{2}^{*}\right) \times \Gamma_{2}\left(\widetilde{y}_{2}, \tau_{1}, \tau_{2}, \tau_{1}^{*}, \tau_{2}^{*}\right) \\
=\arg \max _{\left(\tau_{1}, \tau_{2}\right) ;\left(\tau_{1}, \tau_{2}\right) \in \mathcal{T}^{2}\left(\widetilde{y}_{1}, \widetilde{y}_{2}\right)} \Gamma_{1}\left(\widetilde{y}_{1}, \tau_{1}, \tau_{2}, \tau_{1}^{*}, \tau_{2}^{*}\right) .
\end{gathered}
$$

Given the equal gains condition, the Nash-bargaining criterion amounts to maximize the gain of one delegate.

We show that:

Proposition 9 A Nash-bargained equal gains $I A\left(\tau_{1}^{g}, \tau_{2}^{g}\right)$ is unique and such that:

(i) $\tau_{j}^{g}$ is a decreasing function of $\widetilde{y}_{j}$,

(ii) $\tau_{j}^{g}$ is a decreasing function of $\widetilde{y}_{-j}$ if $\theta<1$, and $\tau_{j}^{g}$ is an increasing function of $\widetilde{y}_{-j}$ if $\theta>1$.

Proof See Appendix I.

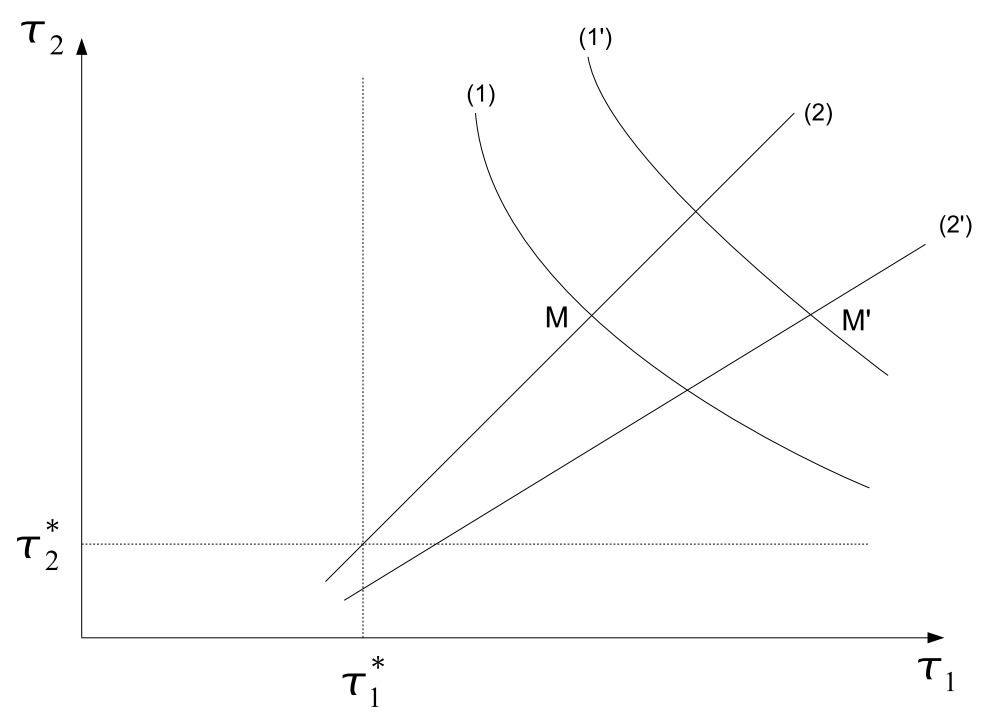

Figure 3: Impact of a decrease of $\tilde{y}_{1}$ 
This proposition details the impact of a variation of a delegate's income on the equal gain IA, when it is bargained according to the Nash-bargaining criterion.

Formally the equal gain IA satisfies two conditions:

$$
\begin{aligned}
\frac{H^{\prime}\left(\tau_{1}\right)}{\tilde{y}_{1}}+\frac{H^{\prime}\left(\tau_{2}\right)}{\tilde{y}_{2}} & =1 \\
\tilde{y}_{1}\left(\tau_{1}-\tau_{1}^{*}\right) & =\tilde{y}_{2}\left(\tau_{2}-\tau_{2}^{*}\right)
\end{aligned}
$$

The first one corresponds to the contract curve (the set of Pareto-optima), i.e. Curve (1) in Figure 3; it is decreasing and convex. The second one corresponds to the equal gain conditions; it is an increasing straight line, i.e. Line (2) in Figure 3.

Suppose that $\tilde{y}_{1}$ decreases. The contract curve moves up (Curve (1') in Fig 3): $\tau_{2}$ must increase for a given $\tau_{1}$. Since $\tau_{1}^{*}$ is increased, the delegate in country 1 is willing to tax more in the case of no-cooperation. For a given pair of tax rates, his gain is reduced. To restore it, for a given tax rate $\tau_{1}$ it is necessary that the tax rate in the other country is increased. The equal gains line is moved to the right as $\tau_{1}^{*}$ is increased and its slope is decreased too (Line (2') in Fig 3). As $\tau_{1}^{*}$ is increased, for a given pair of tax rates, the gain for the country 1's delegate is decreased. So as to keep the gains equal, the tax rate in the other country has to be decreased. Hence the two moves are in the same direction: the intersection of the two curves is moved to the right: $\tau_{1}$ is increased. However this does not imply that $\tau_{2}$ is either moving up or moving down. The move of the contract curve makes it move up, the move of the equal gains line makes it move down. This generates the ambiguity in the answer of $\tau_{2}$ to the increase of $\tilde{y}_{1}$. Given the multiple effects at stake, it happens that it is a positive function if $\theta$ is bigger than 1 , that is if the marginal impact of an increase in $\tau$ on public good provision is sufficiently low.

\subsection{Delegating.}

Now let us study the political aspects of an equal gains IA. As in the case of R1, we want to know first who are the decisive voters, when a particular electoral rule is applied, and second who are sent by the decisive voters. The following proposition addresses both issues in the case of the simple majority rule.

Proposition 10 (i) For any $\theta$, under a simple majority election rule, in each country, the Condorcet winner is the median voter.

(ii) If $\theta \geq 1$, in each country there is strategic delegation as the chosen delegate is richer than the median voter.

\section{Proof See Appendix J.}

Assuming that the electoral rule is the simple majority rule, we get that in both countries the Condorcet winner is the median voter. This comes from the singlecrossing property. Hence the richest half of the electorate in country $j$ prefers to 
vote for the delegate proposed by the median voter than for the delegate proposed by a poorer individual.

Then we can prove that there may exist strategic delegation in this case. Under the assumption that $\theta \geq 1$, we have seen (from Proposition 9) that the two tax rates move in opposite directions when a richer delegate is chosen in a given country. Even if they are forced to reach the same gains for their delegates, the two Condorcet winners play non-cooperatively when they choose their delegates. Each of them wants to make the most out of the other country, that is make it finance the largest possible amount of the public good. By sending a richer delegate, each median voter gets a lower tax rate in his own country and forces the other to support a higher tax rate. Both effects are in favor of this voter. The same argument functions in both countries. The equilibrium of the delegation stage is strategic delegation with richer delegates than the two median voters. This mechanism works even if the two median voters are characterized by equal incomes.

When $\theta$ is less than 1 , the issue is unclear as the tax rate $\tau_{-j}^{g}$ is now a decreasing function of the delegate's income in country $j$. Hence it may happen that the two effects compensate and there is no strategic delegation. This explains why we cannot conclude unambiguously in this case.

\section{Conclusion.}

From the preceeding analysis, it should be clear that the negotiation of an international agreement is fraught with difficulties and there is no wonder some do not take off the ground, or are hotly disputed. From an economist's point of view, the roots of these difficulties, sometimes insuperable, are to be found in the distributive aspects linked with these agreements. What makes the reaching of an agreement so challenging is the necessity to take care of these issues in each of the involved countries.

Building on a model of a two-country economy with a common public good to be financed by contributions from both countries, we have been able to be more precise on these redistributive considerations, internal to sovereign countries. On the whole, the fate of an agreement on a financing scheme depends on the interaction between the political institutions, specific to each nation, the constraints imposed on the negotiators, the negotiation process itself, and last but not least, the inequality schedules in both countries.

We analysed this model using a political economy perspective. We assumed a two-stage sequential game, where the delegates are chosen by elections taking place in each country and then bargain according to the Nash-bargaining criterion (with equal weights). By so doing we have been able to reach a series of results which can be summarized as follows:

- An international agreement on the financing of a common public good implies more taxation effort in both countries than would be the case if no agreement is reached (non cooperation). 
- There always exist agreements which are "feasible", that is that improve the lot of both policymakers, without additional institutional constraints.

- An international agreement involves differentiated gains and losses to different individuals in different countries. There may be winners and losers in both countries. An international agreement is necessarily linked to distributive issues.

- An international agreement may not be reached, if the constraints on the negotiation process are considered too demanding by one national delegate.

- This is the case if an equal tax rates rule is imposed on the negotiation process. Under such a constraint, if an agreement is reached, it is likely to be linked to strategic delegation. That is, at least one decisive voter (the voter who is critical in the selection of her country's delegate) chooses not to delegate himself. Such a move is a way for this decisive voter to maximize his welfare.

- If an equal gains rule is imposed, an international agreement always exists. Assuming a simple majority rule, both median voters are the Condorcet winners. There may be strategic delegation in both countries.

Even though a global public good provision generates non-ambiguously positive externalities, the financing of the global public good impacts households in a differentiated way. The burden of this provision is unequally spread over the entire set of agents. Therefore voters act strategically with the aim of free-riding and shifting the financial burden over other agents, in particular those living in another country. In other words, it is impossible to disentangle the allocative effects of an international agreement from its redistributive effects as they jointly determine the political attitude that any voter adopts with respect to the issue.

Given the various institutional features which matter in the shaping of an international agreement, our analysis makes clear that the terms of the agreement reflect the distribution schedule at the world level, that is the entire $\left\{y_{i}\right\}_{i=1, \ldots N}$. More precisely inequality both within countries and between countries matters. A few polar examples will make this point clearer.

Suppose that both countries are characterized by the same distribution of income: we could say that there is no between-country inequality, but only within-country inequality. Then we can easily draw from our general analysis the following features: the two median voters will be the Condorcet winners; there will be an agreement even if R1 is imposed, as symmetry makes this rule equivalent to R2; however the non-cooperative choice of delegates will induce the median voters to select a richer delegate when $\theta$ is bigger than 1 .

Suppose now that there is strict equality within each country but that households in country 2 are richer than in country 1 . Then by construction there will be no strategic delegation in any country. However, under R1, it may happen that no agreement can be established. 
When both within-country and between-country inequalities exist, the result of the political process, be it an agreement or not, will be affected by both income distributions, as was made clear with our discussion of the equal tax rates rule. To prove Proposition 7 under such a rule, we assumed that every agent in Country 2 was richer than any agent in Country 1 . Such an assumption can easily be viewed as expressing a strong between-country inequality.

In light of these results, and in particular of the different implications of rules $\mathrm{R} 1$ and $\mathrm{R} 2$, it is clear that the mandates imposed on the delegates whose task is to negotiate an international agreement are critical for the success or failure of this negotiation. Some constraints may actually hinder the capacity to find an agreement. This is particularly the case for constraints imposed on the range of instruments to be used, or some links between them.

A priori, if any constraint is to be imposed on the negotiators to limit somehow their power, the advantages and inconveniences of instrument-based rules and objective-based rules can be contrasted.

On the one hand, an objective-based rule such as the equal gains rule we have studied, has the advantage that it is likely to lead to an IA. In the case of the equal-gains rule, it is always the case. However such a result has been obtained under the assumption of no uncertainty, and more generally perfect and complete information. In other words, there is no need to address the issue of verifiability. Without uncertainty or informational defects, there cannot be any misrepresentation of utility functions, nor utility gains derived from a strategic misrepresentation of his objectives by any delegate. However in an uncertain world or in a world where the information sets of agents are incomplete and/or imperfect, it is different. Now the verifiability issue becomes of paramount importance and may be insuperable. A mandate on objectives is likely to generate a lot of opportunistic behaviors, at every stage of the decision process. This is its major defect.

On the other hand, in such a world, the advantage, and maybe the superiority, of a constraint put on the use of instruments becomes clear: the setting of instruments by the involved countries is (more) easily verifiable, so as the enforcement of the agreement by the various countries. Its drawback is that such a rule may lead to no-agreement, because it is impossible to reconcile the objectives of the delegates.

The advantages and inconveniences of these rules are just opposite. We do not intend to pursue on this issue: this is left for further research. Working with a perfect information assumption is useful as a benchmark, providing the challenging results we have just summarized. We are confident that the main message of the present paper will remain in more elaborate settings: These results are the outcomes of the interaction between the political process and the economic structure.

Given the complexity of the subject, the present framework can be extended in several directions. We have already mentioned the possibility to investigate different bargaining procedures or different rules binding the delegates. Another topic of interest is a different specification of the model, with either more complex utility functions, involving multiple differentiated public goods. 
Two issues are worth a few additional words. Some international agreements, because of national constitutional provisions or because of their importance are international treaties negotiated by governmental executives and then ratified by Parliaments or through referenda. Ratification can be seen as an ex post control by Parliaments or the electorates of the work done by the delegates. Hence it is consistent with a very different sequential game than the one we considered here, which could be seen as an a priori commitment to bargain by the electorates, which then select carefully their delegates. The difference introduced by these two ways to handle international agreements is an important topic to study.

Finally we mentioned above the issues of uncertainty and information. This opens the issue of agency problems. Clearly, many such problems can be linked with international agreements: about the preferences of the delegates, about the state of the economy, about the implementation of an agreement, and so on. All this is beyond the scope of the present paper, despite (or because) of its interest and complexity. 


\section{Appendix}

\section{A Proof of Proposition 1.}

The preferred tax rate of an agent of income $y$ in country 1 is $\tau_{1}^{*}(y)$ such that

$\tau_{1}^{*}(y)=\arg \max _{\tau_{1}} F\left(y, \tau_{1}\right)$ where $F\left(y, \tau_{1}\right)=y\left(1-\tau_{1}\right)+H\left(\tau_{1}\right)$.

The first order condition is $y=H^{\prime}\left(\tau_{1}\right)$.

The decision maker of country 1 has an income $\widetilde{y}_{1}$, and so will choose $\tau_{1}=\tau_{1}^{*}$ such that $\widetilde{y}_{1}=H^{\prime}\left(\tau_{1}^{*}\right)$.

$H$ is a concave function, thus $\widetilde{y}_{1}=H^{\prime}\left(\tau_{1}^{*}\right)$ is a decreasing function of $\tau_{1}^{*}$.

\section{B Proof of Proposition 2.}

- If $\left(\tau_{1}, \tau_{2}\right) \in \mathcal{T}\left(\widetilde{y}_{1}, \widetilde{y}_{2}\right)$, then $\Gamma_{1} \geq 0$ and $\Gamma_{2} \geq 0$, where:

$$
\begin{aligned}
\Gamma_{1} & =\Gamma_{1}\left(\widetilde{y}_{1}, \tau_{1}, \tau_{2}, \tau_{1}^{*}, \tau_{2}^{*}\right) \\
& =\left[W\left(\widetilde{y}_{1}, \tau_{1}, \tau_{2}\right)-W\left(\widetilde{y}_{1}, \tau_{1}^{*}, \tau_{2}\right)\right]+\left[W\left(\widetilde{y}_{1}, \tau_{1}^{*}, \tau_{2}\right)-W\left(\widetilde{y}_{1}, \tau_{1}^{*}, \tau_{2}^{*}\right)\right] .
\end{aligned}
$$

The first bracket is always negative since $\tau_{1}^{*}=\arg \max _{\tau_{1}} W\left(\widetilde{y}_{1}, \tau_{1}, \tau_{2}\right)$ for all $\tau_{2}$, and the sum of the 2 brackets is positive since $\Gamma_{1} \geq 0$, thus the second bracket must be positive, i.e. $F\left(\widetilde{y}_{1}, \tau_{1}^{*}\right)+H\left(\tau_{2}\right) \geq F\left(\widetilde{y}_{1}, \tau_{1}^{*}\right)+H\left(\tau_{2}^{*}\right)$, i.e. $H\left(\tau_{2}\right) \geq H\left(\tau_{2}^{*}\right)$, which gives $\tau_{2} \geq \tau_{2}^{*}$ because $H$ is an increasing function. Similarly one can find $\tau_{1} \geq \tau_{1}^{*}$.

$$
\begin{aligned}
& \Gamma_{1}=\Gamma_{1}\left(\widetilde{y}_{1}, \tau_{1}, \tau_{2}, \tau_{1}^{*}, \tau_{2}^{*}\right)=F\left(\widetilde{y}_{1}, \tau_{1}\right)+H\left(\tau_{2}\right)-F\left(\widetilde{y}_{1}, \tau_{1}^{*}\right)-H\left(\tau_{2}^{*}\right) . \\
& \Gamma_{1}=0 \Leftrightarrow H\left(\tau_{2}\right)=F\left(\widetilde{y}_{1}, \tau_{1}^{*}\right)+H\left(\tau_{2}^{*}\right)-F\left(\widetilde{y}_{1}, \tau_{1}\right)
\end{aligned}
$$
i.e.

$\Gamma_{1}=0 \Leftrightarrow \tau_{2}=H^{-1}\left(\widetilde{F}\left(\tau_{1}\right)\right)$, where $\widetilde{F}\left(\tau_{1}\right)=F\left(\widetilde{y}_{1}, \tau_{1}^{*}\right)+H\left(\tau_{2}^{*}\right)-F\left(\widetilde{y}_{1}, \tau_{1}\right)$ is an increasing convex function on $\tau_{1} \in\left[\tau_{1}^{*} ; 1\right]$.

$H^{-1}$ is an increasing convex function, then $\psi_{1}\left(\tau_{1}\right)=H^{-1}\left(\widetilde{F}\left(\tau_{1}\right)\right)$ defines an increasing convex function on $\left[\tau_{1}^{*} ; 1\right]$.

$$
\psi_{1}\left(\tau_{1}^{*}\right)=\tau_{2}^{*} \text { and } \psi_{1}^{\prime}\left(\tau_{1}^{*}\right)=\frac{\widetilde{F}^{\prime}\left(\tau_{1}^{*}\right)}{H^{\prime}\left(H^{-1}\left(\widetilde{F}\left(\tau_{1}^{*}\right)\right)\right)}=\frac{\widetilde{F}^{\prime}\left(\tau_{1}^{*}\right)}{H^{\prime}\left(\tau_{2}^{*}\right)}=0
$$

Similarly, we show that $\Gamma_{2}=0 \Leftrightarrow \tau_{1}=\psi_{2}\left(\tau_{2}\right)$, where $\psi_{2}$ is an increasing convex function on $\left[\tau_{2}^{*} ; 1\right]$, and $\psi_{2}\left(\tau_{2}^{*}\right)=\tau_{1}^{*}$.

$\mathcal{T}\left(\widetilde{y}_{1}, \widetilde{y}_{2}\right)=\left\{\left(\tau_{1}, \tau_{2}\right) \in\left[\tau_{1}^{*}, 1\right] \times\left[\tau_{2}^{*}, 1\right] ; \tau_{2} \geq \psi_{1}\left(\tau_{1}\right)\right\} \cap\left\{\left(\tau_{1}, \tau_{2}\right) \in\left[\tau_{1}^{*}, 1\right] \times\right.$ $\left.\left[\tau_{2}^{*}, 1\right] ; \tau_{1} \geq \psi_{2}\left(\tau_{2}\right)\right\}$.

$\mathcal{T}\left(\widetilde{y}_{1}, \widetilde{y}_{2}\right)$ is a convex set since it is the intersection of two convex sets. It is clearly a closed set, being the intersection of the closed sets $\left\{\Gamma_{1} \geq 0\right\}$ and $\left\{\Gamma_{2} \geq 0\right\}$.

- Now we want to show that $\mathcal{T}_{+}\left(\widetilde{y}_{1}, \widetilde{y}_{2}\right) \neq \varnothing$.

Let $\left.\left.\left.\left.\left(\tau_{1}, \tau_{2}\right) \in\right] \tau_{1}^{*} ; 1\right] \times\right] \tau_{2}^{*} ; 1\right]$. We set $h_{i}=\tau_{i}-\tau_{i}^{*}>0$, for $i=1 ; 2$.

$$
\begin{aligned}
& \Gamma_{1}=\Gamma_{1}\left(\widetilde{y}_{1}, \tau_{1}, \tau_{2}, \tau_{1}^{*}, \tau_{2}^{*}\right)=F\left(\widetilde{y}_{1}, \tau_{1}\right)+H\left(\tau_{2}\right)-F\left(\widetilde{y}_{1}, \tau_{1}^{*}\right)-H\left(\tau_{2}^{*}\right) \\
& =F\left(\widetilde{y}_{1}, \tau_{1}\right)-F\left(\widetilde{y}_{1}, \tau_{1}^{*}\right)+H\left(\tau_{2}\right)-H\left(\tau_{2}^{*}\right) \\
& =\frac{\partial F}{\partial \tau}\left(\widetilde{y}_{1}, \tau_{1}^{*}\right) h_{1}+o\left(h_{1}\right)+H^{\prime}\left(\tau_{2}^{*}\right) h_{2}+o\left(h_{2}\right) \quad \text { as } h_{1} \rightarrow 0^{+} \text {and } h_{2} \rightarrow 0^{+} .
\end{aligned}
$$


$=H^{\prime}\left(\tau_{2}^{*}\right) h_{2}+o\left(h_{1}\right)+o\left(h_{2}\right) \quad$ since $\tau_{1}^{*}=\arg \max _{\tau_{1}} F\left(\widetilde{y}_{1}, \tau_{1}\right)$

$=H^{\prime}\left(\tau_{2}^{*}\right) h+o(h) \quad$ as $h \rightarrow 0$ for $h=h_{1}=h_{2}$.

$\Gamma_{1}=H^{\prime}\left(\tau_{2}^{*}\right) h+o(h)$ with $H^{\prime}\left(\tau_{2}^{*}\right)>0$ thus $\Gamma_{1}>0$ for $h>0$ close to 0.

We can write the same proof for $\Gamma_{2}>0$.

Thus $\Gamma_{1}>0$ and $\Gamma_{2}>0$ for $h=h_{1}=h_{2}>0$ close to 0, i.e. $\mathcal{T}_{+}\left(\widetilde{y}_{1}, \widetilde{y}_{2}\right) \neq \varnothing$.

$\mathcal{T}_{+}\left(\widetilde{y}_{1}, \widetilde{y}_{2}\right)$ is an open set since $\left\{\Gamma_{1}>0\right\}$ and $\left\{\Gamma_{2}>0\right\}$ are open sets.

\section{Proof of Proposition 3.}

Let $\left(\tau_{1}, \tau_{2}\right)$ be a strongly feasible agreement, i.e. such that $\Gamma_{1}\left(\widetilde{y}_{1}, \tau_{1}, \tau_{2}, \tau_{1}^{*}, \tau_{2}^{*}\right)>0$ and $\Gamma_{2}\left(\widetilde{y}_{2}, \tau_{1}, \tau_{2}, \tau_{1}^{*}, \tau_{2}^{*}\right)>0$.

- First, we want to show that there exists $\left.\widehat{y}_{1} \in\right] \widetilde{y}_{1} ;+\infty\left[\right.$ such that for $i \in \mathbf{C}_{1}$, we have $y_{i}>\widehat{y}_{1} \Leftrightarrow \Gamma_{1}\left(y_{i}, \tau_{1}, \tau_{2}, \tau_{1}^{*}, \tau_{2}^{*}\right)<0$.

We must show that $y \mapsto \Gamma_{1}\left(y, \tau_{1}, \tau_{2}, \tau_{1}^{*}, \tau_{2}^{*}\right)$ is a decreasing function.

$\Gamma_{1}\left(y, \tau_{1}, \tau_{2}, \tau_{1}^{*}, \tau_{2}^{*}\right)=W\left(y, \tau_{1}, \tau_{2}\right)-W\left(y, \tau_{1}^{*}, \tau_{2}^{*}\right)=y\left(1-\tau_{1}\right)+H\left(\tau_{1}\right)+H\left(\tau_{2}\right)-$ $y\left(1-\tau_{1}^{*}\right)-H\left(\tau_{1}^{*}\right)-H\left(\tau_{2}^{*}\right)$.

$\frac{\partial}{\partial y} \Gamma_{1}\left(y, \tau_{1}, \tau_{2}, \tau_{1}^{*}, \tau_{2}^{*}\right)=\tau_{1}^{*}-\tau_{1}<0$ thus $y \mapsto \Gamma_{1}\left(y, \tau_{1}, \tau_{2}, \tau_{1}^{*}, \tau_{2}^{*}\right)$ is a decreasing function.

Moreover, $\Gamma_{1}\left(\widetilde{y}_{1}, \tau_{1}, \tau_{2}, \tau_{1}^{*}, \tau_{2}^{*}\right)>0$ and $\lim _{y \rightarrow+\infty} \Gamma_{1}\left(y, \tau_{1}, \tau_{2}, \tau_{1}^{*}, \tau_{2}^{*}\right)=-\infty$.

Thus there exists a unique $\widehat{y}_{1}$, such that $y>\widehat{y}_{1} \Leftrightarrow \Gamma_{1}\left(y, \tau_{1}, \tau_{2}, \tau_{1}^{*}, \tau_{2}^{*}\right)<0$ (and $\left.\widehat{y}_{1}>\widetilde{y}_{1}\right)$, where $\widehat{y}_{1}$ is characterized by $\Gamma_{1}\left(\widehat{y}_{1}, \tau_{1}, \tau_{2}, \tau_{1}^{*}, \tau_{2}^{*}\right)=0$.

- We have $\Gamma_{1}\left(\widehat{y}_{1}, \tau_{1}, \tau_{2}, \tau_{1}^{*}, \tau_{2}^{*}\right)=\widehat{y}_{1}\left(\tau_{1}^{*}-\tau_{1}\right)+H\left(\tau_{1}\right)+H\left(\tau_{2}\right)-H\left(\tau_{1}^{*}\right)-H\left(\tau_{2}^{*}\right)=0$, then:

$$
\widehat{y}_{1}=\frac{1}{\left(\tau_{1}-\tau_{1}^{*}\right)}\left[H\left(\tau_{1}\right)+H\left(\tau_{2}\right)-H\left(\tau_{1}^{*}\right)-H\left(\tau_{2}^{*}\right)\right] .
$$

According to Proposition 1 , we know that $\tau_{j}^{*}$ is a decreasing function of $\widetilde{y}_{j}$.

$\widehat{y}_{1}$ is a decreasing function of $\tau_{2}^{*}$, thus it is clearly an increasing function of $\widetilde{y}_{2}$.

Moreover:

$$
\begin{aligned}
& \frac{d \widehat{y}_{1}}{d \tau_{1}^{*}}=\frac{1}{\left(\tau_{1}-\tau_{1}^{*}\right)^{2}}\left[-H^{\prime}\left(\tau_{1}^{*}\right)\left(\tau_{1}-\tau_{1}^{*}\right)+\left(H\left(\tau_{1}\right)+H\left(\tau_{2}\right)-H\left(\tau_{1}^{*}\right)-H\left(\tau_{2}^{*}\right)\right)\right] \\
& =\frac{1}{\left(\tau_{1}-\tau_{1}^{*}\right)^{2}}\left[-\widetilde{y}_{1}\left(\tau_{1}-\tau_{1}^{*}\right)+\widehat{y}_{1}\left(\tau_{1}-\tau_{1}^{*}\right)\right]=\frac{\widehat{y}_{1}-\widetilde{y}_{1}}{\left(\tau_{1}-\tau_{1}^{*}\right)}>0 .
\end{aligned}
$$

Thus $\widehat{y}_{1}$ is an increasing function of $\tau_{1}^{*}$, and consequently a decreasing function of $\widetilde{y}_{1}$.

- Similar proofs are valid for $\Gamma_{2}$ and $\widehat{y}_{2}$.

\section{Proof of Proposition 4.}

- For $\left(\widetilde{y}_{1}, \widetilde{y}_{2}\right)$ and thus $\left(\tau_{1}^{*}, \tau_{2}^{*}\right)$ given, we set $\gamma_{1}(\tau)=\Gamma_{1}\left(\widetilde{y}_{1}, \tau, \tau, \tau_{1}^{*}, \tau_{2}^{*}\right)$ and $\gamma_{2}(\tau)=$ $\Gamma_{2}\left(\widetilde{y}_{2}, \tau, \tau, \tau_{1}^{*}, \tau_{2}^{*}\right)$.

Let us assume for example that $\widetilde{y}_{1} \leq \widetilde{y}_{2}$, i.e. that $\tau_{1}^{*} \geq \tau_{2}^{*}$.

$$
\begin{aligned}
& \gamma_{j}(\tau)=\widetilde{y}_{j}(1-\tau)+2 H(\tau)-\widetilde{y}_{j}\left(1-\tau_{j}^{*}\right)-H\left(\tau_{1}^{*}\right)-H\left(\tau_{2}^{*}\right) \text { for any } j \\
& \gamma_{1}(\tau)-\gamma_{2}(\tau)=\widetilde{y}_{1}\left(\tau_{1}^{*}-\tau\right)-\widetilde{y}_{2}\left(\tau_{2}^{*}-\tau\right) \\
& \gamma_{1}\left(\tau_{2}^{*}\right)-\gamma_{2}\left(\tau_{2}^{*}\right)=\widetilde{y}_{1}\left(\tau_{1}^{*}-\tau_{2}^{*}\right) \geq 0
\end{aligned}
$$




$$
\gamma_{1}^{\prime}(\tau)-\gamma_{2}^{\prime}(\tau)=\widetilde{y}_{2}-\widetilde{y}_{1} \geq 0
$$

thus $\left(\gamma_{1}-\gamma_{2}\right)(\tau) \geq 0$ for all $\tau \geq \tau_{2}^{*}$.

This means that there is an agreement iff Country 2 agrees, i.e. there is an agreement iff :

$\exists \tau, \gamma_{2}(\tau)>0$, i.e. iff $\gamma_{2}\left(\tau_{2}^{* *}\right)>0$, where $\tau_{2}^{* *}=\arg \max _{\tau} \gamma_{2}(\tau)$.

- With $H(\tau)=\frac{\tau^{1-\theta}}{1-\theta}$ for $\theta \neq 1$, we have:

$$
\begin{aligned}
& \gamma_{2}(\tau)=\widetilde{y}_{2}\left(\tau_{2}^{*}-\tau\right)+2 \frac{\tau^{1-\theta}}{1-\theta}-\frac{1}{1-\theta}\left[\left(\tau_{1}^{*}\right)^{1-\theta}+\left(\tau_{2}^{*}\right)^{1-\theta}\right] \\
& \gamma_{2}^{\prime}(\tau)=-\widetilde{y}_{2}+2 \tau^{-\theta}=-\left(\tau_{2}^{*}\right)^{-\theta}+2 \tau^{-\theta} \\
& \gamma_{2}^{\prime}(\tau) \geq 0 \Leftrightarrow \tau \leq 2^{1 / \theta} \tau_{2}^{*}
\end{aligned}
$$

thus $\tau_{2}^{* *}=2^{1 / \theta} \tau_{2}^{*}$

$$
\begin{aligned}
& \gamma_{2}\left(\tau_{2}^{* *}\right)=\widetilde{y}_{2}\left(\tau_{2}^{*}-\tau_{2}^{* *}\right)+2 \frac{\left(\tau_{2}^{* *}\right)^{1-\theta}}{1-\theta}-\frac{1}{1-\theta}\left[\left(\tau_{1}^{*}\right)^{1-\theta}+\left(\tau_{2}^{*}\right)^{1-\theta}\right] \\
& =\left(\tau_{2}^{*}\right)^{-\theta}\left(\tau_{2}^{*}-2^{1 / \theta} \tau_{2}^{*}\right)+\frac{1}{1-\theta}\left[2 \times\left(2^{1 / \theta} \tau_{2}^{*}\right)^{1-\theta}-\left(\tau_{1}^{*}\right)^{1-\theta}-\left(\tau_{2}^{*}\right)^{1-\theta}\right] \\
& =\left(\tau_{2}^{*}\right)^{1-\theta}\left[1-2^{1 / \theta}+\frac{1}{1-\theta}\left(2 \times 2^{\frac{1-\theta}{\theta}}-1-\left(\frac{\tau_{1}^{*}}{\tau_{2}^{*}}\right)^{1-\theta}\right)\right] \\
& \gamma_{2}\left(\tau_{2}^{* *}\right)=\frac{\left(\tau_{2}^{*}\right)^{1-\theta}}{1-\theta}\left[\theta\left(2^{1 / \theta}-1\right)-\left(\frac{\tau_{1}^{*}}{\tau_{2}^{*}}\right)^{1-\theta}\right] .
\end{aligned}
$$

- If $\theta>1$,

$$
\begin{aligned}
& \gamma_{2}\left(\tau_{2}^{* *}\right) \leq 0 \Leftrightarrow \theta\left(2^{1 / \theta}-1\right) \geq\left(\frac{\tau_{1}^{*}}{\tau_{2}^{*}}\right)^{1-\theta}=\left(\frac{\widetilde{y}_{2}}{\widetilde{y}_{1}}\right)^{\frac{1-\theta}{\theta}} \\
& \gamma_{2}\left(\tau_{2}^{* *}\right) \leq 0 \Leftrightarrow \frac{\widetilde{y}_{2}}{\widetilde{y}_{1}} \geq\left(\theta\left(2^{1 / \theta}-1\right)\right)^{\frac{\theta}{1-\theta}}=b(\theta) .
\end{aligned}
$$

- If $\theta<1$,

$$
\begin{aligned}
& \gamma_{2}\left(\tau_{2}^{* *}\right) \leq 0 \Leftrightarrow \theta\left(2^{1 / \theta}-1\right) \leq\left(\frac{\tau_{1}^{*}}{\tau_{2}^{*}}\right)^{1-\theta}=\left(\frac{\widetilde{\underline{y}}_{2}}{\widetilde{y}_{1}}\right)^{\frac{1-\theta}{\theta}} \\
& \gamma_{2}\left(\tau_{2}^{* *}\right) \leq 0 \Leftrightarrow \frac{\widetilde{y}_{2}}{\widetilde{y}_{1}} \geq\left(\theta\left(2^{1 / \theta}-1\right)\right)^{\frac{\theta}{1-\theta}}=b(\theta) .
\end{aligned}
$$

In both cases, delegate 2 rejects the agreement iff $\frac{\widetilde{y}_{2}}{\widetilde{y}_{1}}>b(\theta)$.

A similar proof is valid if we assume that $\widetilde{y}_{1} \geq \widetilde{y}_{2}$.

- With $H(\tau)=\ln \tau$, i.e. if $\theta=1$, we obtain the same result with $b(1)=\frac{4}{e}$.

This completes the proof of Proposition 4.

\section{E Proof of Proposition 5.}

$\tau^{r}$ is defined as follows: $\tau^{r}=\arg \max _{\tau} \gamma(\tau)$, where $\gamma(\tau)=\gamma_{1}(\tau) \gamma_{2}(\tau)$

We consider $\tau \in\left\{\tau ; \gamma_{1}(\tau)>0\right.$ and $\left.\gamma_{2}(\tau)>0\right\}$

and

$$
\begin{aligned}
& \gamma_{j}(\tau)=\widetilde{y}_{j}\left(\tau_{j}^{*}-\tau\right)+\frac{1}{1-\theta}\left[2 \tau^{1-\theta}-\left(\tau_{1}^{*}\right)^{1-\theta}-\left(\tau_{2}^{*}\right)^{1-\theta}\right] \\
& =\left(\tau_{j}^{*}\right)^{-\theta}\left(\tau_{j}^{*}-\tau\right)+\frac{1}{1-\theta}\left[2 \tau^{1-\theta}-\left(\tau_{1}^{*}\right)^{1-\theta}-\left(\tau_{2}^{*}\right)^{1-\theta}\right]
\end{aligned}
$$

$$
\begin{aligned}
& \gamma_{j}^{\prime}(\tau)=-\left(\tau_{j}^{*}\right)^{-\theta}+2 \tau^{-\theta} \\
& \gamma^{\prime \prime}{ }_{j}(\tau)=-2 \theta \tau^{-\theta-1}<0
\end{aligned}
$$

i.e. $\gamma_{j}$ is strictly concave, for any $j$. Thus $\ln \gamma_{j}$ and $\ln \gamma=\ln \gamma_{1}+\ln \gamma_{2}$ are strictly 
concave, so that $\tau^{r}=\arg \max _{\tau} \ln \gamma(\tau)$ exists and is unique.

We set $\Omega(\tau)=\gamma^{\prime}(\tau)=\gamma_{1}^{\prime}(\tau) \gamma_{2}(\tau)+\gamma_{1}(\tau) \gamma_{2}^{\prime}(\tau)$

The first order condition gives $\Omega\left(\tau^{r}\right)=0$, with $\gamma_{1}\left(\tau^{r}\right)>0$ and $\gamma_{2}\left(\tau^{r}\right)>0$, thus $\gamma_{1}^{\prime}\left(\tau^{r}\right)$ and $\gamma_{2}^{\prime}\left(\tau^{r}\right)$ have opposite signs.

Thus $\Omega^{\prime}\left(\tau^{r}\right)=\gamma^{\prime \prime}{ }_{1}(\tau) \gamma_{2}(\tau)+2 \gamma_{1}^{\prime}(\tau) \gamma_{2}^{\prime}(\tau)+\gamma_{1}(\tau) \gamma^{\prime \prime}{ }_{2}(\tau)<0$

This implies that $\frac{d \tau^{r}}{d \widetilde{y}_{2}}=\frac{\frac{\partial \Omega}{\partial \widetilde{y}_{2}}}{-\frac{\partial \Omega}{\partial \tau}}$ has the sign of $\frac{\partial \Omega}{\partial \widetilde{y}_{2}}$, which has the sign opposite to $\frac{\partial \Omega}{\partial \tau_{2}^{*}}$ (since $\tau_{2}^{*}$ is a decreasing function of $\widetilde{y}_{2}$ ).

thus

$$
\frac{\partial \Omega}{\partial \tau_{2}^{*}}=\frac{\partial}{\partial \tau_{2}^{*}}\left(\gamma_{1}^{\prime}(\tau) \gamma_{2}(\tau)+\gamma_{1}(\tau) \gamma_{2}^{\prime}(\tau)\right)
$$

$$
\frac{\partial \Omega}{\partial \tau_{2}^{*}}=\gamma_{1}^{\prime}(\tau)\left[\theta\left(\tau_{2}^{*}\right)^{-\theta-1}\left(\tau-\tau_{2}^{*}\right)\right]-\left(\tau_{2}^{*}\right)^{-\theta} \gamma_{2}^{\prime}(\tau)+\theta \gamma_{1}(\tau)\left(\tau_{2}^{*}\right)^{-\theta-1}
$$

- If $\widetilde{y}_{1}<\widetilde{y}_{2}$, then $\gamma_{1}^{\prime}(\tau)>0>\gamma_{2}^{\prime}(\tau)$. The three terms in the RHS of (11) are positive and $\frac{\partial \Omega}{\partial \tau_{2}^{*}}>0$. Thus $\frac{\partial \Omega}{\partial \widetilde{y}_{2}}<0$, i.e. $\tau^{r}$ is a decreasing function of $\widetilde{y}_{2}$.

- If $\widetilde{y}_{1}>\widetilde{y}_{2}$, then $\gamma_{2}^{\prime}(\tau)>0>\gamma_{1}^{\prime}(\tau)$. Hence in Equation (11), we see that the first two terms are negative and the third one is positive. This generates the ambiguity.

\section{F Proof of Proposition 6.}

- First we show that in each country, under majority rule, the median voter is the Condorcet winner.

It is sufficient to show that the preferences are single peaked.

Since $\left(\mathbf{C}_{1} \times \mathbf{C}_{2}\right) \cap \mathcal{C}(\theta)=\varnothing$, the chosen delegates $\left(\widetilde{y}_{1}, \widetilde{y}_{2}\right)$ will satisfy $\left(\widetilde{y}_{1}, \widetilde{y}_{2}\right) \notin \mathcal{C}(\theta)$. According to Proposition 4 , it means that no agreement will be reached. The non cooperative tax rates are implemented.

We set $\widehat{W^{1}}\left(y_{1}, \widetilde{y}_{1}, \widetilde{y}_{2}\right)=W^{1}\left(y_{1}, \tau^{r}, \tau^{r}\right)$

where

$$
\widehat{W^{1}}\left(y_{1}, \widetilde{y}_{1}, \widetilde{y}_{2}\right)=y_{1}\left(1-\tau_{1}^{*}\left(\widetilde{y}_{1}\right)\right)+H\left(\tau_{1}^{*}\left(\widetilde{y}_{1}\right)\right)+H\left(\tau_{2}^{*}\right)=y_{1}\left(1-\widetilde{y}_{1}^{-\frac{1}{\theta}}\right)+\frac{1}{1-\theta} \widetilde{y}_{1}^{-\frac{(1-\theta)}{\theta}}+
$$
$H\left(\tau_{2}^{*}\right)$.

Setting $g\left(\widetilde{y}_{1}\right)=y_{1}\left(1-\widetilde{y}_{1}^{-\frac{1}{\theta}}\right)+\frac{1}{1-\theta} \widetilde{y}_{1}^{-\frac{(1-\theta)}{\theta}}$, we have $g^{\prime}\left(\widetilde{y}_{1}\right)=\frac{1}{\theta} \widetilde{y}_{1}^{-\frac{1}{\theta}-1}\left(y_{1}-\widetilde{y}_{1}\right)$ which means that $g$ is an increasing function on $\widetilde{y}_{1} \in\left[0 ; y_{1}\right]$, and a decreasing function on $\left[y_{1} ;+\infty[\right.$, i.e. it is single peaked.

- For given $y_{m_{2}}$ and $\widetilde{y}_{2}$, the welfare of an agent of income $y_{m_{1}}$ in country 1 is:

$$
\widehat{W^{1}}\left(y_{m_{1}}, \widetilde{y}_{1}, \widetilde{y}_{2}\right)=W^{1}\left(y_{m_{1}}, \tau_{1}^{*}\left(\widetilde{y}_{1}\right), \tau_{2}^{*}\right)=y_{m_{1}}\left(1-\tau_{1}^{*}\left(\widetilde{y}_{1}\right)\right)+H\left(\tau_{1}^{*}\left(\widetilde{y}_{1}\right)\right)+H\left(\tau_{2}^{*}\right)
$$

where $\tau_{1}^{*}\left(\widetilde{y}_{1}\right)$ is a decreasing function of $\widetilde{y}_{1}$.

An agent $y_{m_{1}}$ selects a delegate who maximizes $\widehat{W^{1}}\left(y_{m_{1}}, \widetilde{y}_{1}, \widetilde{y}_{2}\right)$, i.e. such that $\tau_{1}^{*}\left(\widetilde{y}_{1}\right)=\arg \max _{\tau_{1}^{*}} y_{m_{1}}\left(1-\tau_{1}^{*}\right)+H\left(\tau_{1}^{*}\right)$.

It means that he chooses a delegate $\widetilde{y}_{1}$ such that $\tau_{1}^{*}\left(\widetilde{y}_{1}\right)=\tau_{1}^{*}\left(y_{m_{1}}\right)$. This implies that $\widetilde{y}_{1}=y_{m_{1}}$ : there is no strategic delegation. 


\section{G Proof of Proposition 7 .}

- First we show that, in the case of simple majority rule, the median voter is the Condorcet winner in Country 2.

It is sufficient to show that the preferences are single peaked.

Here we set $\widehat{W^{2}}\left(y_{2}, \widetilde{y}_{1}, \widetilde{y}_{2}\right)=W^{2}\left(y_{2}, \tau^{r}, \tau^{r}\right)=y_{2}\left(1-\tau^{r}\right)+\frac{2}{1-\theta} \cdot\left(\tau^{r}\right)^{1-\theta}$

where $\tau^{r}=\tau^{r}\left(\widetilde{y}_{1}, \widetilde{y}_{2}\right)$.

Given the assumption we made, we have $\widetilde{y}_{1}<\widetilde{y}_{2}$ thus $\frac{d \tau^{r}}{d \widetilde{y}_{2}}<0$ according to Proposition 5 .

An agent characterized by income $y_{2}$ prefers a delegate $\widetilde{y}_{2}$ maximizing (for $\widetilde{y}_{1}$ given):

$$
\max _{\widetilde{y}_{2}} W^{2}\left(y_{2}, \tau^{r}\left(\widetilde{y}_{1}, \widetilde{y}_{2}\right), \tau^{r}\left(\widetilde{y}_{1}, \widetilde{y}_{2}\right)\right)=\max _{\widetilde{y}_{2}}\left[y_{2}\left(1-\tau^{r}\left(\widetilde{y}_{1}, \widetilde{y}_{2}\right)\right)+\frac{2}{1-\theta} \cdot\left(\tau^{r}\left(\widetilde{y}_{1}, \widetilde{y}_{2}\right)\right)^{1-\theta}\right] .
$$

We set $B_{2}=\frac{d}{d \widetilde{y}_{2}}\left(W^{2}\left(y_{2}, \tau^{r}\left(\widetilde{y}_{1}, \widetilde{y}_{2}\right), \tau^{r}\left(\widetilde{y}_{1}, \widetilde{y}_{2}\right)\right)\right)=\frac{d \tau^{r}}{d \widetilde{y}_{2}}\left[-y_{2}+\frac{2}{\left(\tau^{r}\right)^{\theta}}\right]$.

For $\widetilde{y}_{1}$ and $y_{2}$ given, we get:

$$
\begin{aligned}
& B_{2}=0 \text { for }\left(\tau^{r}\right)^{\theta}=\frac{2}{y_{2}} \\
& B_{2}>0 \text { for }\left(\tau^{r}\right)^{\theta}>\frac{2}{y_{2}} \\
& B_{2}<0 \text { for }\left(\tau^{r}\right)^{\theta}<\frac{2}{y_{2}}
\end{aligned}
$$

where $\tau^{r}$ is a decreasing function of $\widetilde{y}_{2}$,

thus $B_{2}>0$ for $\widetilde{y}_{2}$ small, and $B_{2}<0$ for $\widetilde{y}_{2}$ large, for $\widetilde{y}_{1}$ fixed.

We can conclude that preferences are single peaked in Country 2 , so the median voter is a Condorcet winner in Country 2.

- Let us show now that there is strategic delegation in Country 2.

The median voter $y_{m_{2}}$ of Country 2 prefers a delegate $\widetilde{y}_{2}$ maximizing:

$$
W^{2}\left(y_{m_{2}}, \tau^{r}\left(\widetilde{y}_{1}, \widetilde{y}_{2}\right), \tau^{r}\left(\widetilde{y}_{1}, \widetilde{y}_{2}\right)\right)=y_{m_{2}}\left(1-\tau^{r}\left(\widetilde{y}_{1}, \widetilde{y}_{2}\right)\right)+\frac{2}{1-\theta} \cdot\left(\tau^{r}\left(\widetilde{y}_{1}, \widetilde{y}_{2}\right)\right)^{1-\theta}
$$

(for $\widetilde{y}_{1}$ and $y_{m_{2}}$ given).

We set $B_{2}^{m}=\frac{d}{d \widetilde{y}_{2}}\left(W^{2}\left(y_{m_{2}}, \tau^{r}\left(\widetilde{y}_{1}, \widetilde{y}_{2}\right), \tau^{r}\left(\widetilde{y}_{1}, \widetilde{y}_{2}\right)\right)\right)=\frac{d \tau^{r}}{d \widetilde{y}_{2}}\left[-y_{m_{2}}+\frac{2}{\left(\tau^{r}\right)^{\theta}}\right]$, where $\frac{d \tau^{r}}{d \widetilde{y}_{2}}<0$.

Three cases may arise

(i) right corner solution $\Leftrightarrow B_{2}^{m}>0$, i.e. $\left(\tau^{r}\right)^{\theta}>\frac{2}{y_{m_{2}}}$, and $\widetilde{y}_{2}=y_{2}^{\max }$

(ii) left corner solution $\Leftrightarrow B_{2}^{m}<0$, i.e. $\left(\tau^{r}\right)^{\theta}<\frac{2}{y_{m_{2}}}$, and $\widetilde{y}_{2}=y_{2}^{\min }$

(iii) interior solution $\Leftrightarrow B_{2}^{m}=0$, i.e. $\left(\tau^{r}\right)^{\theta}=\frac{2}{y_{m_{2}}}$

In all cases, $\gamma^{\prime}\left(\tau^{r}\right)=\gamma_{1}^{\prime}\left(\tau^{r}\right) \gamma_{2}\left(\tau^{r}\right)+\gamma_{1}\left(\tau^{r}\right) \gamma_{2}^{\prime}\left(\tau^{r}\right)=0$ thus $\gamma_{1}^{\prime}\left(\tau^{r}\right)=\frac{2}{\left(\tau^{r}\right)^{\theta}}-\widetilde{y}_{1}$ and $\gamma_{2}^{\prime}\left(\tau^{r}\right)=\frac{2}{\left(\tau^{r}\right)^{\theta}}-\widetilde{y}_{2}$ have opposite signs. As $\widetilde{y}_{1}<\widetilde{y}_{2}, \widetilde{y}_{1} \leq \frac{2}{\left(\tau^{r}\right)^{\theta}} \leq \widetilde{y}_{2}$.

Let us study these three cases (i), (ii) and (iii)

(i) gives $\widetilde{y}_{2}=y_{2}^{\max }>y_{m_{2}}$, so there is strategic delegation.

(ii) $y_{m_{2}}<\frac{2}{\left(\tau^{r}\right)^{\theta}}$ and $\widetilde{y}_{2}=y_{2}^{\min }$, thus $y_{2}^{\min }=\widetilde{y}_{2} \geq \frac{2}{\left(\tau^{r}\right)^{\theta}}>y_{m_{2}}$ which is impossible.

(iii) $y_{m_{2}}=\frac{2}{\left(\tau^{r}\right)^{\theta}} \leq \widetilde{y}_{2}$.

There is strategic delegation when $\frac{2}{\left(\tau^{r}\right)^{\theta}}<\widetilde{y}_{2}$. 
Let us show that $y_{m_{2}}=\frac{2}{\left(\tau^{r}\right)^{\theta}}=\widetilde{y}_{2}$, is impossible. If $y_{m_{2}}=\frac{2}{\left(\tau^{r}\right)^{\theta}}=\widetilde{y}_{2}$, then $\gamma_{1}^{\prime}\left(\tau^{r}\right)=\frac{2}{\left(\tau^{r}\right)^{\theta}}-\widetilde{y}_{1}=\widetilde{y}_{2}-\widetilde{y}_{1}$.

But $\gamma^{\prime}\left(\tau^{r}\right)=0$ and $\gamma_{2}^{\prime}\left(\tau^{r}\right)=0$, thus $\gamma_{2}\left(\tau^{r}\right)=0$. Let us show that this last case is impossible.

We know that $\widetilde{y}_{j}=\left(\tau_{j}^{*}\right)^{-\theta}$. We have:

$\gamma_{2}\left(\tau^{r}\right)=\left(\tau_{2}^{*}\right)^{-\theta}\left(\tau_{2}^{*}-\tau^{r}\right)+\frac{1}{1-\theta}\left[2\left(\tau^{r}\right)^{1-\theta}-\left(\tau_{1}^{*}\right)^{1-\theta}-\left(\tau_{2}^{*}\right)^{1-\theta}\right]=\widetilde{y}_{2}\left(\tau_{2}^{*}-\tau^{r}\right)+$ $\frac{1}{1-\theta}\left[\widetilde{y}_{2} \tau^{r}-\tau_{1}^{*} \widetilde{y}_{1}-\tau_{2}^{*} \widetilde{y}_{2}\right]$

which leads to

$$
\gamma_{2}\left(\tau^{r}\right)=\widetilde{y}_{2}\left(\tau_{2}^{*}-\tau^{r}\right)\left[1-\frac{1}{1-\theta}\right]-\frac{\tau_{1}^{*} \widetilde{y}_{1}}{1-\theta}=\widetilde{y}_{2}\left(\tau_{2}^{*}-\tau^{r}\right)\left(\frac{-\theta}{1-\theta}\right)-\frac{\tau_{1}^{*} \widetilde{y}_{1}}{1-\theta} .
$$

If $\gamma_{2}\left(\tau^{r}\right)=0$, thus $\tau_{1}^{*} \widetilde{y}_{1}=\widetilde{y}_{2}\left(\tau^{r}-\tau_{2}^{*}\right) \theta$, i.e. $\widetilde{y}_{1}^{1-\frac{1}{\theta}}=\widetilde{y}_{2}^{1-\frac{1}{\theta}}\left(\frac{\tau^{r}-\tau_{2}^{*}}{\tau_{2}^{*}}\right)$

which implies

$\left(\frac{\widetilde{\underline{y}}_{2}}{\widetilde{y}_{1}}\right)^{(1-\theta) / \theta}=\left(2^{1 / \theta}-1\right) \theta$, that is: $\frac{\widetilde{y}_{2}}{\widetilde{y}_{1}}=\left[\theta\left(2^{1 / \theta}-1\right)\right]^{\theta /(1-\theta)}$.

It means that the ratio $\frac{\widetilde{y}_{2}}{\widetilde{y}_{1}}$ is in the boundary of $\mathcal{C}(\theta)$, which is excluded by assumption.

\section{H Proof of Proposition 8.}

$\left(\tau_{1}, \tau_{2}\right)$ is an equal gains strongly feasible agreement iff:

$\Gamma_{1}\left(\widetilde{y}_{1}, \tau_{1}, \tau_{2}, \tau_{1}^{*}, \tau_{2}^{*}\right)=\Gamma_{2}\left(\widetilde{y}_{2}, \tau_{1}, \tau_{2}, \tau_{1}^{*}, \tau_{2}^{*}\right)>0$

In that case, we necessarily have $\tau_{1}>\tau_{1}^{*}$ and $\tau_{2}>\tau_{2}^{*}$.

We know that $\Gamma_{1}\left(\widetilde{y}_{1}, \tau_{1}^{*}, \tau_{2}^{*}, \tau_{1}^{*}, \tau_{2}^{*}\right)=\Gamma_{2}\left(\widetilde{y}_{2}, \tau_{1}^{*}, \tau_{2}^{*}, \tau_{1}^{*}, \tau_{2}^{*}\right)=0$

For $\left(\widetilde{y}_{1}, \widetilde{y}_{2}, \tau_{1}^{*}, \tau_{2}^{*}\right)$ given, we set:

$$
\begin{aligned}
& \widetilde{G}\left(\tau_{1}, \tau_{2}\right)=\Gamma_{2}\left(\widetilde{y}_{2}, \tau_{1}, \tau_{2}, \tau_{1}^{*}, \tau_{2}^{*}\right)-\Gamma_{1}\left(\widetilde{y}_{1}, \tau_{1}, \tau_{2}, \tau_{1}^{*}, \tau_{2}^{*}\right)=\widetilde{y}_{2}\left(\tau_{2}^{*}-\tau_{2}\right)-\widetilde{y}_{1}\left(\tau_{1}^{*}-\tau_{1}\right) \\
& \widetilde{G}\left(\tau_{1}, \tau_{2}\right)=0 \Leftrightarrow \tau_{2}=\tau_{2}^{*}+\frac{\widetilde{y}_{1}}{\widetilde{y}_{2}}\left(\tau_{1}-\tau_{1}^{*}\right)
\end{aligned}
$$

thus for $\varepsilon>0$ small enough, if $\left.\tau_{1} \in\right] \tau_{1}^{*} ; \tau_{1}^{*}+\varepsilon\left[\right.$ and $\tau_{2}=\tau_{2}^{*}+\frac{\widetilde{y}_{1}}{\widetilde{y}_{2}}\left(\tau_{1}-\tau_{1}^{*}\right)$, then $\left(\tau_{1}, \tau_{2}\right) \in \mathcal{T}_{+}^{1}\left(\widetilde{y}_{1}, \widetilde{y}_{2}\right)$

\section{Proof of Proposition 9.}

$\Gamma_{1}\left(\widetilde{y}_{1}, \tau_{1}, \tau_{2}, \tau_{1}^{*}, \tau_{2}^{*}\right)=\widetilde{y}_{1}\left(\tau_{1}^{*}-\tau_{1}\right)+H\left(\tau_{1}\right)+H\left(\tau_{2}\right)-H\left(\tau_{1}^{*}\right)-H\left(\tau_{2}^{*}\right)$

thus

$$
\Gamma_{1}\left(\widetilde{y}_{1}, \tau_{1}, \tau_{2}, \tau_{1}^{*}, \tau_{2}^{*}\right)-\Gamma_{2}\left(\widetilde{y}_{2}, \tau_{1}, \tau_{2}, \tau_{1}^{*}, \tau_{2}^{*}\right)=\widetilde{y}_{1}\left(\tau_{1}^{*}-\tau_{1}\right)-\widetilde{y}_{2}\left(\tau_{2}^{*}-\tau_{2}\right)
$$

To maximize $\Gamma_{1}\left(\widetilde{y}_{1}, \tau_{1}, \tau_{2}, \tau_{1}^{*}, \tau_{2}^{*}\right) \times \Gamma_{2}\left(\widetilde{y}_{2}, \tau_{1}, \tau_{2}, \tau_{1}^{*}, \tau_{2}^{*}\right)$ under the constraint

$$
\Gamma_{1}\left(\widetilde{y}_{1}, \tau_{1}, \tau_{2}, \tau_{1}^{*}, \tau_{2}^{*}\right)=\Gamma_{2}\left(\widetilde{y}_{2}, \tau_{1}, \tau_{2}, \tau_{1}^{*}, \tau_{2}^{*}\right)
$$

is of course equivalent to maximize $\Gamma_{1}\left(\widetilde{y}_{1}, \tau_{1}, \tau_{2}, \tau_{1}^{*}, \tau_{2}^{*}\right)$ under the same constraint.

There exists a maximum since $\mathcal{T}^{2}\left(\widetilde{y}_{1}, \widetilde{y}_{2}\right)$ is a compact set.

The Lagrangian of the last program is:

$$
\begin{aligned}
& \mathcal{L}_{\mu}\left(\widetilde{y}_{1}, \widetilde{y}_{2}, \tau_{1}, \tau_{2}, \tau_{1}^{*}, \tau_{2}^{*}\right)=\Gamma_{1}\left(\widetilde{y}_{1}, \tau_{1}, \tau_{2}, \tau_{1}^{*}, \tau_{2}^{*}\right)-\mu\left(\Gamma_{2}\left(\widetilde{y}_{2}, \tau_{1}, \tau_{2}, \tau_{1}^{*}, \tau_{2}^{*}\right)-\Gamma_{1}\left(\widetilde{y}_{1}, \tau_{1}, \tau_{2}, \tau_{1}^{*}, \tau_{2}^{*}\right)\right) \\
& =\widetilde{y}_{1}\left(\tau_{1}^{*}-\tau_{1}\right)+H\left(\tau_{1}\right)+H\left(\tau_{2}\right)-H\left(\tau_{1}^{*}\right)-H\left(\tau_{2}^{*}\right)-\mu\left[\widetilde{y}_{2}\left(\tau_{2}^{*}-\tau_{2}\right)-\widetilde{y}_{1}\left(\tau_{1}^{*}-\tau_{1}\right)\right]
\end{aligned}
$$


Hence the gradient of $\mathcal{L}_{\mu}$ is equal to:

$$
\nabla \mathcal{L}_{\mu}\left(\widetilde{y}_{1}, \widetilde{y}_{2}, \tau_{1}, \tau_{2}, \tau_{1}^{*}, \tau_{2}^{*}\right)=\left(\begin{array}{l}
-\widetilde{y}_{1}+H^{\prime}\left(\tau_{1}\right)-\mu \widetilde{y}_{1} \\
H^{\prime}\left(\tau_{2}\right)+\mu \widetilde{y}_{2}
\end{array}\right)
$$

and we get

$$
\exists \mu, \nabla \mathcal{L}_{\mu}\left(\widetilde{y}_{1}, \widetilde{y}_{2}, \tau_{1}, \tau_{2}, \tau_{1}^{*}, \tau_{2}^{*}\right)=0 \Leftrightarrow \frac{H^{\prime}\left(\tau_{1}\right)}{\widetilde{y}_{1}}+\frac{H^{\prime}\left(\tau_{2}\right)}{\widetilde{y}_{2}}=1
$$

The Lagrangian is strictly concave since $H_{e s s} \mathcal{L}_{\mu}$ is definite negative, thus there exists a unique maximum $\left(\tau_{1}^{g}, \tau_{2}^{g}\right)$. It is the unique solution of the system

$$
\left\{\begin{array}{c}
\frac{H^{\prime}\left(\tau_{1}\right)}{\widetilde{y}_{1}}+\frac{H^{\prime}\left(\tau_{2}\right)}{\widetilde{y}_{2}}=1 \\
\widetilde{y}_{1}\left(\tau_{1}^{*}-\tau_{1}\right)=\widetilde{y}_{2}\left(\tau_{2}^{*}-\tau_{2}\right)
\end{array}\right.
$$

where $\widetilde{y}_{j}=H^{\prime}\left(\tau_{j}^{*}\right)=\left(\tau_{j}^{*}\right)^{-\theta}$ and $H^{\prime}\left(\tau_{j}\right)=\left(\tau_{j}\right)^{-\theta}$.

$\left(\tau_{1}^{g}, \tau_{2}^{g}\right)$ is then the solution of

$$
(\mathcal{G})\left\{\begin{array}{c}
\left(\frac{\tau_{1}^{*}}{\tau_{1}}\right)^{\theta}+\left(\frac{\tau_{2}^{*}}{\tau_{2}}\right)^{\theta}=1 \\
\frac{\tau_{1}^{*}-\tau_{1}}{\left(\tau_{1}^{*}\right)^{\theta}}=\frac{\tau_{2}^{*}-\tau_{2}}{\left(\tau_{2}^{*}\right)^{\theta}}
\end{array}\right.
$$

Let $G_{1}\left(\tau_{1}, \tau_{2}\right)=\left(\frac{\tau_{1}^{*}}{\tau_{1}}\right)^{\theta}+\left(\frac{\tau_{2}^{*}}{\tau_{2}}\right)^{\theta}-1$ and $G_{2}\left(\tau_{1}, \tau_{2}\right)=\frac{\tau_{1}^{*}-\tau_{1}}{\left(\tau_{1}^{*}\right)^{\theta}}-\frac{\tau_{2}^{*}-\tau_{2}}{\left(\tau_{2}^{*}\right)^{\theta}}$, and $G=\left(\begin{array}{c}G_{1} \\ G_{2}\end{array}\right)$ $(\mathcal{G})$ define a system of implicit functions. According to the implicit function theorem (for a system of 2 functions), for $\tau_{2}^{*}$ given:

$\exists \varphi=\left(\varphi_{1}, \varphi_{2}\right)$ functions, such that $(\mathcal{G}) \Leftrightarrow\left\{\begin{array}{l}\tau_{1}=\varphi_{1}\left(\tau_{1}^{*}, \tau_{2}^{*}\right) \\ \tau_{2}=\varphi_{2}\left(\tau_{1}^{*}, \tau_{2}^{*}\right)\end{array}\right.$ for $\left(\tau_{1}, \tau_{2}\right)$ in an open set,

and we have $\left(\begin{array}{c}\frac{d \tau_{1}}{d \tau_{1}^{*}} \\ \frac{d \tau_{2}}{d \tau_{1}^{*}}\end{array}\right)=J a c \varphi=-\left(J a c_{\tau} G\right)^{-1}\left(J a c_{\tau_{1}^{*}} G\right)$, where

$$
J a c_{\tau_{1}^{*}} G=\left(\begin{array}{l}
\theta \frac{\left(\tau_{1}^{*}\right)^{\theta-1}}{\tau_{1}^{\theta}} \\
\frac{1-\theta}{\left(\tau_{1}^{*}\right)^{\theta}}+\frac{\theta \tau_{1}}{\left(\tau_{1}^{*}\right)^{\theta+1}}
\end{array}\right) \text { and } J a c_{\tau} G=\left(\begin{array}{cc}
-\theta \frac{\left(\tau_{1}^{*}\right)^{\theta}}{\tau_{1}^{\theta+1}} & -\theta \frac{\left(\tau_{2}^{*}\right)^{\theta}}{\tau_{2}^{\theta+1}} \\
-\frac{1}{\left(\tau_{1}^{*}\right)^{\theta}} & \frac{1}{\left(\tau_{2}^{*}\right)^{\theta}}
\end{array}\right)
$$

Setting $D=-\operatorname{det} J a c_{\tau} G>0$, we have:

and

$$
\left(J a c_{\tau} G\right)^{-1}=\frac{-1}{D}\left(\begin{array}{cc}
\frac{1}{\left(\tau_{2}^{*}\right)^{\theta}} & \theta \frac{\left(\tau_{2}^{*}\right)^{\theta}}{\tau_{2}^{\theta+1}} \\
\frac{1}{\left(\tau_{1}^{*}\right)^{\theta}} & -\theta \frac{\left(\tau_{1}^{*}\right)^{\theta}}{\tau_{1}^{\theta+1}}
\end{array}\right)
$$

$$
\left(\begin{array}{l}
\frac{d \tau_{1}}{d \tau_{1}^{*}} \\
\frac{d \tau_{2}}{d \tau_{1}^{*}}
\end{array}\right)=J a c \varphi=\frac{1}{D}\left(\begin{array}{l}
\theta \frac{\left(\tau_{1}^{*}\right)^{\theta-1}}{\left(\tau_{2}^{*}\right)^{\theta} \tau_{1}^{\theta}}+\frac{\theta(1-\theta)\left(\tau_{2}^{*}\right)^{\theta}}{\left(\tau_{1}^{*}\right)^{\theta} \tau_{2}^{\theta+1}}+\frac{\theta^{2} \tau_{1}\left(\tau_{2}^{*}\right)^{\theta}}{\left(\tau_{1}^{*}\right)^{\theta+1} \tau_{2}^{\theta+1}} \\
\frac{\theta}{\tau_{1}^{*} \tau_{1}^{\theta}}-\frac{(1-\theta) \theta}{\tau_{1}^{\theta+1}}-\frac{\theta^{2}}{\tau_{1}^{*} \tau_{1}^{\theta}}
\end{array}\right)
$$

thus $\frac{d \tau_{1}}{d \tau_{1}^{*}}=\frac{1}{D}\left[\theta \frac{\left(\tau_{1}^{*}\right)^{\theta-1}}{\left(\tau_{2}^{*}\right)^{\theta} \tau_{1}^{\theta}}+\frac{\theta\left(\tau_{2}^{*}\right)^{\theta}}{\left(\tau_{1}^{*}\right)^{\theta+1} \tau_{2}^{\theta+1}}\left(\tau_{1}^{*}+\theta\left(\tau_{1}-\tau_{1}^{*}\right)\right)\right]>0$ and $\frac{d \tau_{2}}{d \tau_{1}^{*}}=\frac{\theta}{D \tau_{1}^{*} \tau_{1}^{\theta+1}}(1-\theta)\left(\tau_{1}-\tau_{1}^{*}\right)$ has the sign of $1-\theta$. 


\section{J Proof of Proposition 10.}

(i) The welfare of an agent of country 1 and of income $y$ is:

$W^{1}\left(y, \tau_{1}^{g}\left(\widetilde{y}_{1}, \widetilde{y}_{2}\right), \tau_{2}^{g}\left(\widetilde{y}_{1}, \widetilde{y}_{2}\right)\right)=y\left(1-\tau_{1}^{g}\left(\widetilde{y}_{1}, \widetilde{y}_{2}\right)\right)+H\left(\tau_{1}^{g}\left(\widetilde{y}_{1}, \widetilde{y}_{2}\right)\right)+H\left(\tau_{2}^{g}\left(\widetilde{y}_{1}, \widetilde{y}_{2}\right)\right)$

For a given $\widetilde{y}_{2}$, this welfare is then a function $\widehat{W^{1}}\left(y, \widetilde{y}_{1}, \widetilde{y}_{2}\right)$ of $y$ and $\widetilde{y}_{1}$, i.e.

$$
\begin{aligned}
& \widehat{W^{1}}\left(y, \widetilde{y}_{1}, \widetilde{y}_{2}\right)=y\left(1-\tau_{1}^{g}\left(\widetilde{y}_{1}, \widetilde{y}_{2}\right)\right)+H\left(\tau_{1}^{g}\left(\widetilde{y}_{1}, \widetilde{y}_{2}\right)\right)+H\left(\tau_{2}^{g}\left(\widetilde{y}_{1}, \widetilde{y}_{2}\right)\right) \\
& \frac{\partial W^{1}}{\partial y}\left(y, \widetilde{y}_{1}, \widetilde{y}_{2}\right)=1-\tau_{1}^{g}\left(\widetilde{y}_{1}, \widetilde{y}_{2}\right) \\
& \frac{\partial^{2} W^{1}}{\partial \widetilde{y}_{1} \partial y}\left(y, \widetilde{y}_{1}, \widetilde{y}_{2}\right)=-\frac{\partial \tau_{1}^{g}}{\partial \widetilde{y}_{1}}\left(\widetilde{y}_{1}, \widetilde{y}_{2}\right)>0
\end{aligned}
$$

thus according to the single crossing property, the median voter theorem applies: the Condorcet winner is the median voter.

(ii) Who will be chosen as delegate by the median voter?

An agent of income $y$ will prefer to send a delegate of income $\widetilde{y}_{1}$ maximizing $\widehat{W^{1}}\left(y, \widetilde{y}_{1}, \widetilde{y}_{2}\right)$.

Let $B=\frac{\partial \widehat{W}^{1}}{\partial \widetilde{y}_{1}}\left(y, \widetilde{y}_{1}, \widetilde{y}_{2}\right)=\frac{\partial \tau_{1}^{g}}{\partial \widetilde{y}_{1}}\left[-y+H^{\prime}\left(\tau_{1}^{g}\right)\right]+\frac{\partial \tau_{2}^{g}}{\partial \widetilde{y}_{1}} H^{\prime}\left(\tau_{2}^{g}\right)$

where $\frac{\partial \tau_{1}^{g}}{\partial \widetilde{y}_{1}}<0, H^{\prime}\left(\tau_{2}^{g}\right)>0$ and $\frac{\partial \tau_{2}^{g}}{\partial \widetilde{y}_{1}}$ has the sign of $\theta-1$.

The first order condition is $B=0$, which leads to $\left[-y+H^{\prime}\left(\tau_{1}^{g}\right)\right]=\frac{\frac{\partial \tau_{2}^{g}}{\partial \widetilde{y}_{1}} H^{\prime}\left(\tau_{2}^{g}\right)}{-\frac{\partial \tau_{1}^{g}}{\partial \tilde{y}_{1}}}$

If $\theta \geq 1$, it means that $\left[-y+H^{\prime}\left(\tau_{1}^{g}\right)\right] \geq 0$, i.e. $y \leq H^{\prime}\left(\tau_{1}^{g}\right)$

Since $H^{\prime}\left(\tau_{1}^{g}\right)<H^{\prime}\left(\tau_{1}^{*}\right)=\widetilde{y}_{1}$, we can conclude that $y<\widetilde{y}_{1}$

Conclusion: if $\theta \geq 1$, any agent (including the median one) prefers to choose a delegate richer than himself. In other words, there is strategic delegation. 


\section{References}

[1] Alesina, A., I. Angeloni, and F. Etro (2005): "International Unions," American Economic Review, 95(3), 602-615.

[2] Barrett, S. (2003): Environment and Statecraft. The strategy of environmental treaty-making, Oxford University Press.

[3] Besley, T., and S. Coate (2003): "Centralized versus Decentralized Provision of Locals: a Political Economy Approach," Journal of Public Economics, 87(12), 2611-2637.

[4] Buchholtz, W., A.Haupt and W. Peters (2005): "International Environmental agreements and strategic voting," Scandivanian Journal of Economics, 107(1), 175-195.

[5] Currarini S. and H. Tulkens (2004): "Stable International Agreements on Transfrontier Pollution under Ratification Constraints", in Carlo Carraro, Vito Fragnelli (eds.), Game Practice and the Environment, Edgar Elgar.

[6] Guzman, A. (2005): "The design of international agreements," The European Journal of International Law, 16(4), 579-612.

[7] Guzman, A. (2008): How International Law Works: a Rational Choice Theoy, Oxford University Press.

[8] Koremenos B. (2005): "Contracting around International Uncertainty," American Political Science Review, 99(2), 549-565.

[9] Koremenos B. (2008): "When, What, and Why do States Choose to Delegate?," Law and Contemporary Problems, 71, 151-92.

[10] Koremenos B., C. Lipson and D. Snidal (2001), " The Rational Design of International Institutions," International Organization 55(4), 761-800.

[11] Langlois, J.-P. and C. Langlois (2006): "Holding Out for Concession: The Quest for Gain in the Negotiation of International Agreements "International Interactions, 32(3), 261-293.

[12] Muthoo, Abhinay (1999): Bargaining Theory with Applications, Cambridge University Press.

[13] Raustiala, K. (2005): "Form and Substance in International Agreements" , American Journal of International Law, 99, 581-614.

[14] Richards, J. E. (2004): "Institutions for flying: How States built a Market in International Aviation Services", in Koremenos, Lipson and Snidal (eds), The Rational Design of International Relations, Cambridge University Press. 
[15] Ringquist, E. J. and T. Kostadinova (2005): “Assessing the Effectiveness of International Environmental Agreements: The Case of the 1985 Helsinki Protocol," American Journal of Political Science, 49(1), 86-102.

[16] Rota-Graziosi, G. (2009): "On the Strategic Use of Representative Democracy in International Agreements", Journal of Public Economic Theory, vol. 11(2), 281-296. 